University of Nebraska - Lincoln

DigitalCommons@University of Nebraska - Lincoln

Management Department Faculty Publications

Management Department

2009

\title{
A framework for examining leadership in extreme contexts
}

\author{
Sean T. Hannah \\ West Point-United States Military Academy, sean.hannah@usma.edu \\ Mary Uhl-Bien \\ University of Nebraska-Lincoln, mbien2@unl.edu \\ Bruce Avolio \\ University of Nebraska - Lincoln, bavolio@u.washington.edu \\ Fabrice L. Cavarretta \\ ESSEC Business School, 95021 Cergy Pontoise, France, Cavarretta@essec.edu
}

Follow this and additional works at: https://digitalcommons.unl.edu/managementfacpub

Part of the Management Sciences and Quantitative Methods Commons

Hannah, Sean T.; Uhl-Bien, Mary; Avolio, Bruce; and Cavarretta, Fabrice L., "A framework for examining leadership in extreme contexts" (2009). Management Department Faculty Publications. 39.

https://digitalcommons.unl.edu/managementfacpub/39

This Article is brought to you for free and open access by the Management Department at DigitalCommons@University of Nebraska - Lincoln. It has been accepted for inclusion in Management Department Faculty Publications by an authorized administrator of DigitalCommons@University of Nebraska - Lincoln. 


\title{
A framework for examining leadership in extreme contexts
}

\author{
Sean T. Hannah ${ }^{\mathrm{a}, *}$, Mary Uhl-Bien ${ }^{\mathrm{b}, 1}$, Bruce J. Avolio ${ }^{\mathrm{c}, 2}$, Fabrice L. Cavarretta ${ }^{\mathrm{d}, 3}$ \\ ${ }^{a}$ West Point-United States Military Academy, Army Center of Excellence for the Professional Military Ethic, West Point, NY, 10996, USA \\ b Global Leadership Institute, College of Business Administration, Department of Management, University of Nebraska-Lincoln, CBA 269. P.O Box 880491, Lincoln, \\ NE 68588-0491, USA \\ c Center for Leadership \& Strategic Thinking, Foster School of Business, University of Washington, Seattle, WA 98195-3200, USA \\ d Management Department, ESSEC Business School, 95021 Cergy Pontoise, France
}

\section{A R T I C L E I N F O}

\section{Keywords:}

Extreme contexts

High reliability

Crisis

Leadership

Danger

\begin{abstract}
A B S T R A C T
In this review, we develop a framework to guide future research and to examine the execution of leadership in extreme contexts. We start by defining and distinguishing extreme contexts from crisis and other contexts. A five component typology is developed comprised of magnitude of consequences, form of threat, probability of consequences, location in time and physical or psychological-social proximity. We discuss the unique influences these components have on leadership processes in extreme contexts examining the relevance of organization types such as critical action and high reliability organizations. Further, we present a set of factors that may attenuate or intensify the dimensions comprising an extreme context, thus influencing either a team or organization's ability for adaptive leadership response. Ultimately this framework seeks to develop a richer understanding of extreme contexts to advance the future development of contextualized theories of leadership for extreme contexts. Published by Elsevier Inc.
\end{abstract}

Stories about leaders often detail how they successfully led their organizations to overcome great challenges or peril. The frequency of these extreme stories would suggest that the field of leadership studies should have a lot to say about how leaders function in extreme contexts. As we will show in this review, that is not the case and in fact leadership in extreme contexts may be one of the least researched areas in the leadership field. Yet, while minimal, some important research has been conducted such as Sorokin's (1943) examination of reactions of groups to catastrophic events, where he concluded that group members became so overly aroused and emotional that they distorted the way they processed information and made decisions. The premise of this paper is that leadership is uniquely contextualized in such extreme contexts where risks of severe physical, psychological or material consequences (e.g., physical harm, devastation or destruction) to organizational members or their constituents exist. In terms of the practical value of our discussing extreme contexts and leadership, while extreme events are rare in some organizations, they are commonplace in others such as military, medical, law enforcement, fire, and crisis response organizations.

Beyond being limited in number, Bass (2008) concluded that the prior research on leadership and groups operating in extreme contexts has tended to treat such situations as homogenous. Responding to Bass' concern, we suggest that before a productive stream of research on leadership for extreme contexts can be initiated, we believe it is critical that we first define what 'context' means here, and to differentiate and decompose extreme contexts such that we can develop a richer understanding of how they contextualize leadership. Taking a contextual focus to examining leadership is not something that is a recent insight. Over the last

\footnotetext{
* Corresponding author. Tel.: +1 8459385945.

E-mail addresses: Sean.Hannah@usma.edu (S.T. Hannah), muhlbien@unlnotes.unl.edu (M. Uhl-Bien), bavolio@u.washington.edu (B.J. Avolio), Cavarretta@essec.edu (F.L. Cavarretta).

1 Tel.: +1 402472 2314; fax: +1 4024725855 .

2 Tel.: +1 2065437909 .

3 Tel.: +33609594674.
} 
two decades scholars have made numerous calls for leadership researchers to take greater account of contextual factors in the formulation of their theories as well as in operational definitions of leadership (e.g., Avolio, 2007; Boal \& Hooijberg, 2000; Shamir \& Howell, 1999; Tosi, 1991). Yet, in a recent review of the literature, Porter and McLaughlin (2006, p. 573) note that "it is apparent that the impact of organization context on leadership is an under-researched area." Ultimately, substantial research in extreme contexts will be required to advance our knowledge in this critically important area of leadership research-perhaps the area where leadership is needed most.

We believe extreme contexts create particularly unique contingencies, constraints and causations; requiring researchers to view such leadership as inherently contextualized. As described by Osborn, Hunt, and Jauch (2002), a contextual theory of leadership is one that recognizes that leadership is embedded and "socially constructed in and from a context" (p. 798), and put it well that, "leadership and its effectiveness, in large part, are dependent upon the context. Change the context and leadership changes" (p. 797). Yet, we will also note that leadership is not just passively influenced by extreme contexts, but can interact with the context and serve to intensify or attenuate levels of extremity. For example, Gal and Jones (1985) argue that leaders who are strong, confident and deliberate will attenuate levels of stress among followers, while also increasing their confidence to perform in extreme contexts over time. Conversely, in their reviews of disasters, Dynes and colleagues (Dynes, 1974; Dynes, Quarantelli, \& Kreps, 1981) argue that besides the disaster itself (e.g., a hurricane), the second major source of negative outcomes come from errors of commission or omission in the organization's and its leaders' actions in response to the disaster and its aftermath.

We make clear that we are not developing a prescribed theory of leadership for extreme contexts. Instead, our intent is more descriptive and seeks to set the stage for advancing future research to develop such prescriptive models by providing researchers with a semantic and conceptual toolbox with which to explore this context itself and its unique influences on leadership. Our hope is that this review makes clear that any theory of leadership for extreme contexts cannot be loosely generalized, but that different forms of extreme contexts exist and different types of organizations engage in extreme contexts; with both creating patterns of dynamics that influence leadership through unique contingencies, constraints and causation.

To guide our efforts, we assessed literature and case studies from a broad range of extreme contexts as well as doctrine from organizations that operate in extreme contexts such as the U.S. Army and National Wildfire Service. ${ }^{4}$ Guided by this review, we began to place some boundaries on what actually constitutes an extreme context-and even more importantly-what does not. We begin by defining and differentiating extreme contexts at the macro level, followed by a discussion of various organization types that operate in extreme contexts and how these types further contextualize leadership at a meso level. From this base of understanding, we begin a detailed exploration of the five dimensions of extreme contexts presented in Fig. 1. We then discuss how various factors can attenuate or intensify levels of extremity and the ability to produce or inhibit an adaptive leadership response. Throughout we seek to highlight the unique influences that various forms of extreme contexts can have on leadership processes with the hope that this knowledge may inform more refined approaches to future leadership research.

\section{Defining and distinguishing extreme contexts}

\subsection{Defining extreme events and extreme contexts}

We start with the assumption that extreme events can occur in any organization, regardless of whether it is operating in what we would traditionally consider an extreme context. For example, serving in the Pentagon prior to 9:39 a.m. on 9/11 was likely not considered to be an extreme context, but it certainly became one after the terrorist attack on this facility. We suggest that unique factors influence leadership in important ways depending on where and when it is occurring relevant to the extreme event and context, and across periods before, during, or after an extreme event.

In defining these terms we suggest the presence or threat of one or more extreme events is a necessary, but not a sufficient condition to constitute an extreme context. We hold that the event(s) must 1) have potential for massive physical, psychological, or material consequences that occur in physical or psycho-social proximity to organization members, 2) the consequences of which are thought unbearable by those organization members, and 3) are such that they may exceed the organization's capacity to prevent those extreme events from actually taking place. Therefore, we define an extreme event as a discrete episode or occurrence that may result in an extensive and intolerable magnitude of physical, psychological, or material consequences to-or in close physical or psycho-social proximity to-organization members. Going beyond an extreme event, we define an extreme context as an environment where one or more extreme events are occurring or are likely to occur that may exceed the organization's capacity to prevent and result in an extensive and intolerable magnitude of physical, psychological, or material consequences to-or in close physical or psycho-social proximity to-organization members.

\footnotetext{
${ }^{4}$ Examples include the Mann Gulch (Weick, 1993) and South Canyon fires (Useem, Cook, \& Sutton, 2005), Indian Ocean Tsunami (Athukorala \& Resosudarmo, 2005; Rodriquez, Wachtendorf, Kendra, \& Trainor, 2006), Bhopal Chemical release (Bowman \& Kunreuther, 1988; Shrivastava, 1987; Union Carbide Report, 1985), Three Mile Island meltdown (Hopkins, 2001; Perrow, 1997), Columbia Space Shuttle explosion (Heimann, 1993; Starbuck \& Miliken, 1988; Vaughan, 1996), Westray mine disaster (Hynes \& Prasad, 1997), Mount Everest climbing incidents (Kayes, 2004; Tempest, Starkey, \& Ennew, 2007), hurricane Katrina (Comfort, 2007; Gheytanchi et al., 2007; Kapucu \& Van Wart, 2006; Rego \& Garau, 2007), Tenerife airplane collision (Weick, 1990), Chernobyl (Hohenemser, Deicher, Ernst, Hofsäss, Lindner, \& Recknagel (1986)), numerous military leadership and combat studies (e.g., Cosby et al., 2006; Morath, Ccurnow, Cronin, Leonard, \& McGonigle, 2006; Leonard, Polich, Peterson, Sorter, \& Moore, 2006; Department of the Army, 1950, 2008; Scales, 2006; Snook, 2000; Ulmer, Shaler, Bullis, DiClemente, \& Jacobs, 2004; Wong, Bliese, \& McGurk, 2003) and organizational doctrine such as the U. S. Army (Department of the Army, 2006) and National Wildfire Service (2007) leadership manuals.
} 


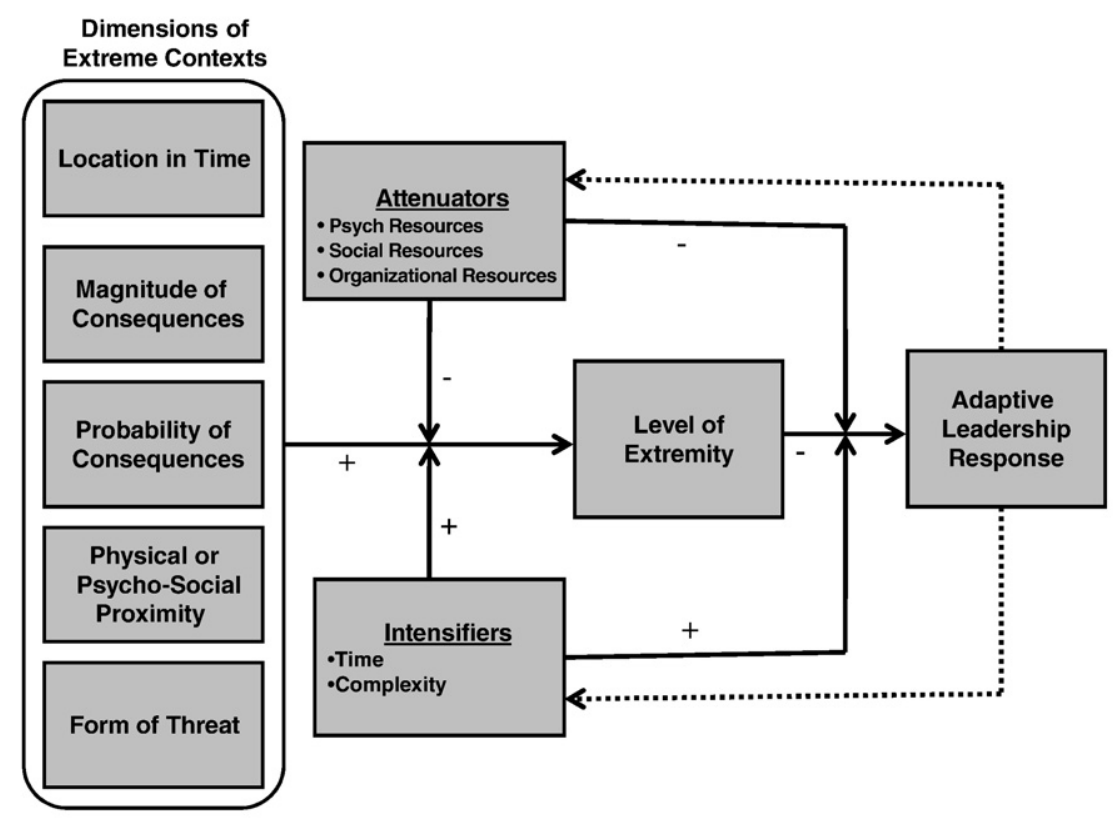

Fig. 1. Typology of extreme contexts.

\subsubsection{Differentiating extreme from crisis}

It is also important to differentiate extreme contexts from the common usage of the term crisis in the literature. Crisis is both a more general term and has also been used to explain relatively mundane contexts. For example, in their model of crisis management, Pearson and Clair (1998) include events spanning from copyright infringement and malicious rumors to natural disasters. Our position is that, while related, extreme contexts are unique from crisis and demand more refined characterization.

The models of organizational context by Jick and Murray (1982) as well as Osborn et al. (2002) used Hermann's (1969) definition of crisis, which states, "a situation that threatens high priority goals... which suddenly occurs with little or no response time available." Pearson and Clair (1998, p. 60) echo these points and add that the event must be "of low probability" and "characterized by ambiguity of cause, effect, and means of resolution." First, these definitions address crisis as if they are episodes, which is akin to how we have framed extreme events (versus an extreme context). Paralleling our earlier logic, we could envision a "crisis context" in which crisis episodes (i.e., crises) are likely to occur. Yet, due to other qualifiers listed below, extreme events may come in the form of a crisis, but are not necessarily in that form.

First, whereas crisis involves the threat to a high priority goal, our definition of extreme contexts is predicated on a stricter qualification. In our definition, such threats must reach the threshold of “intolerable magnitude" where goals (e.g., life or safety) are not just of high priority but are imperative, and at that point unique properties bear on leadership that are not present at lower levels of threat. For example, the relationship between trust-in-leader and follower performance may be fairly linear until the point where a follower may die based on a leader's decisions. This interdependency may create a threshold effect (Chatterjee \& Hambrick, 2007; Sørensen, 2002) where the trust $\rightarrow$ performance linkage becomes unstable and nonlinear. We also propose that when death or other extreme consequences are probable, leaders and followers may alter the meaning of a construct, which would necessitate measuring it differently (Golembiewski \& Billingsley, 1980; Thompson \& Hunt, 1996). For example, followers faced with losing their jobs due to a merger (often called a "crisis" in the literature) will likely conceptualize levels of "trust" quite differently from those following a leader down a burning high rise building hallway, which is considered the most dangerous point in an urban fire. Thus, how we conceptualize the differences in trust may impact the way it's measured.

Second, whereas crisis definitions include little or no response time, we do not see this component as integral to the definition of extreme contexts. ${ }^{5}$ Crises as defined result in reactive responses, but organizations operating in extreme contexts can in fact have foresight over or even control the initiation of an extreme event. This can potentially provide significant periods of preparation, such as the methodical months of force buildup and preparation prior to the U.S. military's planned launch of Operation Desert Storm in 1991.

Third, whereas the definition of crisis considers these situations to be of low probability, extreme events that characterize extreme contexts are not necessarily so. For example, many first responder organizations face extreme events repetitively both in training and in daily operations.

Finally, extreme contexts are not necessarily characterized by ambiguity of cause, effect, and means of resolution. For example, a fire company may know the source of the fire, be able to estimate its speed and direction of spread based on factors such as climate and available fuel, and know the optimum means of resolution. Yet, leadership systems may not be able to implement the

\footnotetext{
${ }^{5}$ Although not required for a context to be classified as extreme, we do later incorporate issues of time in our framework as factors that can serve to intensify an extreme context.
} 
resolution due to a lack of resources, organizational adaptability, training, and/or other factors. Similarly, an organization may have an optimum solution to an extreme event, but be waiting for the "go ahead" from a leader outside the organization (e.g., a politician).

In sum, crisis and extreme contexts are not synonymous. We do recognize that the two can be entrained such that a crisis leads to an extreme context or vice versa. For example, Ember and Ember (1992) note that a crisis can lead to a scarcity of resources (e.g., water) leading to social and moral breakdowns that could promote extreme contexts, such as war, famine, or civil unrest.

\subsubsection{Differentiating extreme contexts from high reliability organizations (HRO)}

The HRO (Weick, Sutcliffe, \& Obstfeld, 1999) and accidents (Perrow, 1984) literatures have contributed extensive knowledge about how organizations address catastrophic events. Later we classify HROs as a form of organization rather than a context; as organizations can move in and out of extreme contexts. Further, we view the definition of extreme contexts as broader than high reliability, which tends to be safety and crisis-prevention orientated. For example, Weick and Sutcliffe (2001) include power grid operations as HROs. Furthermore, our focus is not only on macro organizational levels, but also on the micro and meso-level contexts and consequences of individual organizational actors and groups being exposed to potential threats.

\section{Organization types and contextualization of leadership}

Leaders and followers do not just interact within an extreme context unconstrained, but usually as embedded in an organizational context. This meso-level context is important to recognize because, as discussed by Osborn et al. (2002), "to the extent that leadership is socially constructed within the society and within the firm, the meaning attached to 'leadership' may vary considerably across time and across firms." In the context of disasters, Turner (1976, p. 378) notes that organizations are "cultural mechanisms developed to set collective goals and make arrangements to deploy available resources to attain those goals." Organizations are thus idiosyncratic entities and we propose that the intra-organizational context will interact with the extraorganizational context influencing their ability to respond to threats. Thus different organization types will have different sets of attenuators and abilities to manage intensifiers. To address these issues, we focus on four types of organizational contexts and how they produce unique impacts on leadership when confronting extremity: 1) trauma organizations, 2) critical action organizations 3) high reliability organizations and 4) naïve organizations.

\subsection{Trauma organizations}

In some organizations, such as hospital emergency rooms or ambulance or emergency medical teams, extreme events can occur with great frequency (perhaps hourly or daily). There are some important unique parameters in such organizations. First, they are largely reactive in that they serve to engage after extreme events have occurred. This requires them to be responsive and able to surge resources on little notice and reset quickly for the next extreme event. As these organizations operate in contexts where the probability of extreme events occurring is high, they require high levels of vigilance, situational awareness, and preparedness.

While leaders and followers in these organizations may at times be at risk, the risk is often largely to the client being served. For example, while the form of threat to the client may be physical, to operating room team members, the threat of losing a patient is psychological versus physical. The magnitude of consequences may also vary, with the client facing relatively greater risk. This creates unique dependencies and required trust, as well as inherent moral obligations, which may influence leadership among responding units/members. To sustain effectiveness across frequent iterations of extreme events, these groups may require a certain level of detachment (i.e., limited psychological proximity) from clients or the use of coping mechanisms. Emergency room nurses, for example, must be able to maintain objectivity in triaging patients, as well as mentally detach at shift end and keep the trauma of their work separate from their personal lives.

Moreover, as the frequency and iteration of extreme events is extremely high in trauma organizations, leaders and followers will likely have extensive exposure to how individuals and the group functions under extreme conditions. Indeed over time "extreme" can become "normal" and the group may require interventions to ensure vigilance is maintained (Pauchant \& Mitroff, 1992; Pearson \& Mitroff, 1993). This is because the more experience one has with particular threats, the more likely the same threat will not be perceived as threatening (Benner, 1984). Further, relating to time, while the frequency of events may be high in trauma organizations, the duration is normally relatively low. A doctor may only spend minutes with a patient, or the EMT crew will stabilize then drop a patient off at the hospital. Thus while they must maintain resilience, vigilance and other states across multiple events, this suggests that less may be required within any one extreme event.

Finally, through frequent iterations of similar procedures and processes, trauma organizations have many opportunities for organizational learning. Coupled with their unique responsibility and liability for clients, such organizations may tend to codify standard operating procedures for many routine tasks and establish layers of administrative controls.

\subsection{Critical action organizations}

Critical action organizations (CAO) include organizations such as military combat units, certain clandestine services, or the more active SWAT, fire, search and rescue or disaster response teams. Organizations in this category engage in extreme events but with less frequency relative to trauma organizations. These extreme events, however, may have higher potential magnitude of 
consequences (e.g., combat) with numerous CAO members and often hostile (e.g., enemy or criminal) and non-hostile (e.g., noncombatant civilians) at risk.

Unlike trauma organizations, leaders and followers in CAOs inherently place themselves at greater amounts of personal risk as they perform their duties. Further, if they are in fact serving a "client" (e.g., rescuing a hostage or avalanche victim) CAOs are more likely to share the same form of risk (e.g., physical) as the client. It is thus not surprising most CAOs require members to selfsacrifice if called upon, with this commitment often codified in oaths or codes formed into the organization's culture as a unique ethos (e.g., Department of Army, 2006).

As facing extreme consequences is part of the organization's mission, CAOs may create higher tolerances for risk and loss, making the "intolerable magnitude" aspect of our definition of extreme contexts relative. For example, military units will factor killed and wounded-in-action estimates into mission planning as an unfortunate but necessary reality to combat (VanVactor, 2007). In this way, they differ from the other categories of organizations discussed in this section, which may be less likely to engage if team members can be killed or injured.

As CAOs may engage in extreme events less frequently than trauma organizations, they may require more extensive collective training and simulations. Due to expected casualties, such training requires redundancies and cross-functional training. If a surgeon becomes incapacitated in the operating room during an intricate procedure, for example, another surgeon will need to be located to step in versus a nurse or another member of the operating team. In a CAO, as they operate often under austere conditions or time constraints do not allow personnel replacements, team members must be ready to step up and take the role of other team members or assume formal leadership positions if leaders are lost (Stouffer et al., 1965). This requires a balance between generalization and specialization-necessitating leader development to build the "bench" of leaders.

Further, as CAOs face hostile opposition in the course of their duties, such as enemy forces or criminals, they are further distinguished from trauma organizations who inherently seek to "do no harm." Normal police operations similarly do not actively injure criminals unless in self defense. CAOs, conversely operate in hostile environs where death, injury or destruction may be purposeful. Finally, select CAOs (e.g., military or select clandestine units) may at times proactively create extreme events at a time and place of their choosing. They may select targets, timing and varying usage of force to accomplish goals. This distinguishes select CAOs from other CAOs and more so non-CAOs that react to versus initiate extreme events.

\subsection{High reliability organizations}

Contrary to trauma or CAO organizations, other types of organizations are classified as High Reliability Organizations (HROs) (Weick, 1993; Weick \& Sutcliffe, 2001; Weick, Sutcliffe, \& Obstfeld, 1999). Normal police and fire operations would fit under this category. The overwhelming majority of police officers, for example, will never fire their weapon in the line of duty much less use deadly force (Geller \& Scott, 1992). With respect to fire, as noted by Useem et al. (2005, p. 466) in investigating the South Canyon Fire; standing orders were to fight the fire with aggression, but always considering "safety first." This category also includes organizations that focus on containing or preventing extreme events as a primary function, such as disease control organizations or nuclear power plant operations.

Although of lesser probability than trauma or CAO organizations, HROs may face extreme events if a situation goes outside normal boundaries and thus would likely present unique contingencies and normative constraints on leadership processes that are distinct from those in naïve organizations. Due to their focus toward prevention, HROs may tend to be highly administrative in their controls and well practiced for a wide range of anticipated extreme events (Weick \& Sutcliffe, 2001; Weick, et al., 1999). Therefore, such organizations tend to focus heavily on risk management policies and systems and on tracking indicators that may signal impending systems failures (Glendon, Clarke, \& McKenna, 2006).

Weick and colleagues studied organizations that perform repetitive tasks with little margin for error, such as flight deck operations on aircraft carriers and power grid operators where their research showed such organizations balance speed and efficiency with safety. A differentiation can be made between aircraft flight deck operations, which consistent with Weick we would term an HRO, and the attack aircraft wing that launches from that carrier which we would term a CAO. This is because once they are airborne and on combat mission, while safety remains important, it is subordinate to combat mission accomplishment. Here the factors unique to CAOs (e.g., proactively creating versus avoiding extreme events) may provide contingences and constraints on leadership that differ from HROs.

\subsection{Naïve organizations}

Finally, there are those organizations that are thrust into extreme contexts by chance, such as a hotel faced with a fire or terrorist attack, a passenger plane being hijacked, or a school hit by a tornado. These "normal" organizations may suffer from a lack of training and resources to respond to such events, thus intensifying extremeness. As naïve organizations see low probability of such events occurring; they are less likely to apply resources to prepare for such events. Pauchant and Mitroff (1992) argue that leaders in organizations that see low probability of extreme events occurring often fail to realize the importance of preparation or use defense mechanisms (e.g., 'someone will rescue us') to eschew preparing for such events (e.g., D'Aveni \& MacMillan, 1990; Kiesler \& Sproull, 1982). Yet, given recent world events, we wonder if the number of naïve organizations that may be thrust into an extreme context is growing.

While we have only briefly described each organization type, and done so from a largely intuitive approach, we believe that the discussion highlighted numerous factors researchers might consider that contextualize leadership at this meso/organizational level. Yet, we believe there are some other organizational aspects that should be considered. 


\subsubsection{The people make the place}

It may be important for future research to assess attraction, selection, and attrition (ASA) processes (Schneider, 1987; Schneider, Goldstein, \& Smith, 1995) related to the above types of organizations. It is plausible, if not likely, that each of the four organization types listed above attract and select certain "types" of people and attrite those who do not meet their models. Also, as leadership is socially constructed (Osborn et al., 2002), differential forms of leadership may be developed through social learning as organizations operate in varying types of extreme contexts and learn what they deem to be successful leadership for those contexts. Such implicit leadership theories (Lord, Foti, \& DeVader, 1984) may then influence future ASA cycles, thereby perpetuating those leadership models. While such social learning is required, it may also restrict change (Weick, 1988). Thus the effects of strong cultures on adaptability in extreme contexts warrant attention in future research.

\subsubsection{Extreme organizations, extreme units, and extreme operators}

It is also important to note that we have used the term "organization" quite liberally in our taxonomy and need to qualify that usage. Specifically, categorization as a trauma organization, for example, is in fact level-dependent. It would be inaccurate to describe an entire hospital as a trauma organization or an entire Army as a CAO. Hospitals and military units each have administrative (e.g., janitorial or secretarial) and other sub-organizations that (unless thrust into danger as a naïve organization) do not face threat nor do their actions have direct effects on the potential consequences on clients.

Large organizations are instead multifaceted and thus would likely have subunits that fit the various categories (i.e., trauma, CAO, or HRO), such as the delineation between the carrier flight deck operations and the attack wing made earlier. It may facilitate future research to differentiate elements within organizations based on the factors of extremeness (i.e., probability, magnitude or proximity) between those that directly face extreme contexts (e.g., an attack fighter wing), those that provide direct support to those that do (e.g., a refueling wing) and those that provide indirect support (e.g., airfield operations). Based on the discussion thus far, there is likely unique leadership phenomenon operating within each subgroup or context, resulting in group differences that can inform the theory and practice of leadership.

\section{Overview of the model}

From this general understanding of extreme contexts and extreme events and organization types, we will now discuss extreme contexts in a more specific manner based on the model presented in Fig. 1. The focal construct of the model is the box titled "level of extremity" which we suggest can reduce the ability for adaptive leadership response. Our literature review suggested that the level of extremity experienced by an organization or group is largely based on five primary contextual dimensions as shown. However, we display other factors-that while not necessary for a context to be classified as extreme-can serve to either attenuate or intensify the level of extremity experienced. Attenuators and intensifiers, however, are likely to only partially influence the level of extremity faced. For example, a large fire will likely create high levels of extremity regardless of any attenuators or intensifiers present. Thus we also denote, as displayed by the second set of arrows in Fig. 1, those attenuators and intensifiers (e.g., organizational resources) can also positively or negatively (respectively) influence the ability for adaptive leadership response despite the level of extremity experienced. Importantly, as noted by the dashed lines, we suggest that leaders can potentially influence many of the attenuating and intensifying factors. We begin by discussing each of the five dimensions and the various ways each contextualizes leadership and creates specific contingencies and causation.

\section{Dimensions of extreme contexts}

\subsection{Location in time/temporal ordering}

The first major component of extreme contexts is time. As levels of threat oscillate within an extreme context, we expect a concomitant oscillation of levels of extremity. While conventional wisdom might assume that extremity will be highest during an actual extreme event, history shows that is not necessarily so. For example, the effects of the Chernobyl nuclear power accident is expected to last for more than 30 years due to cancer and other effects (Hohenemser et al., 1986). Similarly, Shrivastava, Mitroff, Miller, and Miglani (1988) report that in the months of aftermath of the Bhopal accident, 2500 people were killed and 200,000 injured; 2000 animals were killed and 7000 injured; and massive amounts of crops and vegetation were destroyed.

Bruning (1964) and Leonard and Howitt (2007) suggest that what constitutes effective leadership will vary over the stages of preparation, response and recovery from an extreme event. We further suggest that leaders may also need to effectively manage the transitions from stable to extreme and back to relatively stable, along the way continually rebalancing the unit or organization with respect to emotional, cognitive and physical perspectives.

\subsubsection{Preparation}

Leadership is critical in preparation for an extreme event to provide foresight, planning, training, and other preparedness efforts (McConnell \& Drennan, 2006; Smits \& Ally, 2003). Pauchant and Mitroff (1992) and Pearson and Mitroff (1993) both highlight the critical roles leaders play to get an organization "crisis prepared." Unless the probability of an extreme event(s) occurring is readily perceived, leaders must overcome human tendencies to believe that "it can't happen to us," where leaders may need to create "cognitive shifts" in their groups (Foldy, Goldman, \& Ospina, 2008) to better realize potential threats and the vigilance and preparedness required. From a sociological perspective, Clarke (2006) argues that "possibilistic thinking" is required 
where, even though an extreme event may be rare, the potential magnitude of consequences warrants planning and preparation. We address these leadership demands in more detail in the section focusing on magnitude of threats.

Also, organizations that infrequently engage in extreme events, such as a police department in a low crime area, may establish routines that result in boredom and may require leaders to intervene to maintain vigilance, motivation and performance such that they are not caught "flat footed" if an extreme event occurs (Grant et al., 2007). The dangers associated with routinization are not restricted to organizations with limited exposure to extreme contexts. Indeed, it can stem from what actually constitutes the nature of exposure for a particular group.

Leonard and Howitt (2007) discuss that organizations can face routine or non-routine extreme events. What is considered routine, however, is likely idiosyncratic to individual organizations as outlined above and the frequency they find themselves in a particular extreme context. For example, in Somalia, Army Rangers had conducted six other successful raids to capture insurgents prior to the ill-fated mission portrayed in Black Hawk Down (Bowden, 1999). Some argue that earlier successful missions created a lack of vigilance; where expecting another rapid daylight mission, some soldiers left their night vision goggles and other equipment and supplies that would later be critically needed behind at their base camp.

During preparation phases teams can leverage debriefings from prior events to prepare for subsequent incursions into future extreme operating contexts. For example, after action reviews for interpreting failures could produce richer and more complex mental models or expert schemas that could facilitate teams in addressing future extreme contexts (Holyoak, 1991; Marks, Zaccaro, \& Mathieu, 2000). Thus, what leaders do after an event in preparation for the next may be as important as what they do in the extreme events in preparing for successful performance.

Finally, some 'technological' extreme events (e.g., Challenger Shuttle, Three Mile Island reactor, or Bhopal chemical spill) may even be caused by organization members. Such failures can stem from breakdowns of mindfulness, sense-making or failure to provide proper training, safeguards, or oversight (Pearson \& Clair, 1998; Perrow, 1997; Turner, 1976; Weick 1988).

Beyond preparing an organization psychologically, Shrivastava et al. (1988) note that during pre-event phases leaders need to prepare the physical and social infrastructure, establish monitoring and surveillance systems, redundant essential services, emergency action plans, medical systems, and other capacities. Further, as poor information exchange and coordination is normally problematic during extreme events (Turner, 1976), it is also critical to establish redundant leadership and communications systems across internal and external networks.

\subsubsection{In situ}

In summarizing 500 field studies of disasters conducted by the Disaster Research Center, Quarantelli (1988, p. 374) notes that the principles of disaster preparation and crisis management are not "two sides of the same coin" and that "there is, in fact, only a partial correlation between the undertaking of preparedness planning and the successful or good management of community disasters." This suggests that as the context transitions from pre-extreme event to in situ, the demands on leadership and what constitutes effective leadership may qualitatively change. For example, in his reflections on men in battle, Gray (1959, chap. 2) notes that combat has a certain lure and appeal for many; as they see it as offering excitement and the exotic, and the ability to serve one's country and test their own mettle. He notes that this excitement, however, is often quickly shattered once the exposure to the horrors of warfare is made and the grim reality of killing or being killed is faced. Leadership has been found to be critical to subsequent performance during this transition (Belenky, Noy, \& Solomon, 1985).

Unlike pre-event phases where leaders may struggle to maintain preparation and vigilance, the levels of extreme intensity in situ may inherently motivate members facing a threat to take action. Indeed, when extremity is high and people sense an immediate and dangerous threat, they are prone to engage more intently (Kolditz, 2007; McKean, 1994), but not necessarily more effectively. For instance, followers are more likely to accept hasty decisions made in threatening situations that may be poorly determined, as well as more centralized, autocratic leadership (Bass, 2008). Therefore, leaders who provide more rapid and authoritative responses may be more likely to be followed, sometimes regardless of the accuracy of their decisions or direction (Mulder, de Jong, Koppeaar, \& Verhage, 1986). In as much as goals are well selected, Mintz (1951) reported that groups with clear goals were better able to work thru crises. This is consistent with Wright's (1946) research showing that aircrews responded to crises better if they perceived they had a common goal and common threat.

We suspect the relationship between the intensity of the event and the motivation of individuals addressing it is likely curvilinear. Specifically, if the extremity is too overwhelming, and/or individuals feel a lack of efficacy they will likely become more susceptible and vulnerable, with some members becoming immobilized due to experiences of terror and other emotive responses to fear (Arndt, Greenberg, Pyszczynski, Solomon, \& Simon, 1997; Bowlby, 1969; Foa \& Kozak, 1986; Janoff-Bulman \& Frieze, 1983; Parks, 1971). This type of immobilization may be reversed by a leader who is dominating and aggressive, acting to quickly reduce the ambiguity associated with events and redirecting followers to action (Fodor, 1978). Yet, even where followers are inherently motivated and feeling efficacious to perform, leaders still face the effects of increased vigilance over time which can create fatigue and physical and mental breakdowns. In combat, for example, leaders often have to force soldiers to sleep, especially junior leaders who feel the weight of command (Department of the Army, 1950). This suggests that shared forms of leadership may become critical to sustaining effective performance in sustained extreme contexts, allowing different leaders to emerge while others recover.

Under extended periods of stress, followers who trust their leader's directives are more likely to sustain focus and effort towards achieving the mission (Sweeney, Thompson, \& Blanton, 2009). As demonstrated in studies in combat (Belenky et al., 1985; Sweeney et al., 2009), under extended and extreme stress, followers' performance will be influenced by their trust in the leader when entering such contexts, how the leader addresses their expectations and concerns, and how they keep them focused 
on the goals for the unit (Bass, 1985). In sum, without a willingness to be vulnerable and open to the leader's directives, units can lose focus and alignment and over time be less prepared to respond.

During the stress of extreme events, organizational systems and processes will also likely be stretched toward or beyond their limits, and organizational roles may be challenged and break down. For example, Weick (1993) attributes the Mann Gulch fire disaster in part to fire fighters disobeying their leader's orders to abandon organizational procedures by dropping their tools and starting counter fires. Torrance (1961) examined military groups undergoing survival training and reported that discounting leaders' directives resulted in cliques or in and out groups and leaders' isolation from the group; resulting in reduced perceived power of the group, failure of the group to share relevant information, and a lack of mutual support and common goals.

For leaders operating in extreme contexts, the trust formed with their units prior to extreme events occurring is critical to how those units subsequently perform. A lack of trust in the integrity of the leader's decisions, even during relatively short crises, can result in the destruction of a unit's level of cohesion and commitment, or at the extreme, mutiny may occur (Hamby, 2002). Indeed, if leadership is weak during non-stressful periods, "it will prove even weaker when disaster strikes" (Quarantelli, 1988, p. 379).

At group level, social factors such as cohesion, organizational identification, commitment and leadership may also serve to mitigate stress and anxiety and maintain performance (Department of the Army, 1950, 2006). Group identification, for example, has been shown to buffer one's fear of death (Strachan et al., 2007). This suggests that such social "resources" would likely need to be built prior to an extreme event. Specifically, Zaccaro, Rittman, and Marks (2001, p. 471) suggest that, "team members are likely to display less emotional reactions to stressors if leaders provide clear team goals, clear specifications of member roles...unambiguous performance strategies, and foster a climate where disagreements about team strategies can be aired constructively."

Further, Weick (1988, p. 305) argues that "the less adequate the sense-making process directed at a crisis, the more likely it is that the crisis will get out of control." This may be why using more transactional/path-goal leadership under such stressful situations may be more effective in keeping events under control as it provides clear step by step directions for followers (Schriesheim \& Murphy, 1976). Supporting this claim, Kugihara, Misumi, Sato, and Shigeoka (1982) observed in simulated panic situations that those leaders who focused more on performance planning and considerations of followers as advocated in pathgoal theory were more successful in removing followers from the dangerous situation.

Yet, complicating how leadership manifests in crisis, Weick proposed that sense-making becomes problematic in extreme events. This is because "understanding is facilitated by action, but action affects events and can make things worse" (p. 306). Weick (1996; 1988) argues that we think by acting and that we must not only believe what we know but at the same time be willing to challenge what we know as we act and learn from those actions. Indeed a fundamental principle of social psychology is thinking stems from doing (Fiske, 1991); however, a corollary of this principle is that doing causes thinking (Weick, 1988; 1996). Thus, cognition and behavior are reciprocal: both are necessary for an extensive repertoire of possible adaptive responses.

As extreme events are often at least somewhat novel, the role leaders take in "sense-giving" to assist followers in sensemaking may be critical (Foldy et al., 2008). Leaders can provide organization members a sense of meaning to "get their bearings and then create fuller, more accurate views of what is happening and what their options are" (Weick, 1988, p. 310). The sensemaking process also underscores the importance of how leaders and followers debrief extreme events as noted earlier. Through experiences and meaning-making, organization members form a set of if-then structures, or a 'causal map' that sets their source of expectations for future action (Weick \& Bougon, 1986). These rich schemata can facilitate processing future extreme events more quickly and effortlessly and be relied upon until an event presents stimuli that are considered nonroutine that must be interpreted using a more controlled processing framework (Fiske, 1991). Thus as more responses to potential extreme events are practiced, greater complexity will be formed in relevant schemas for individuals (Hannah, Woolfolk, \& Lord, 2009; Mumford, Friedrich, Caughron, \& Byrne, 2007; Mumford, Zaccaro, Harding, Jacobs, \& Fleishman, 2000) and ultimately group mental models (Hannah, Eggers, \& Jennings, 2008), promoting naturalistic decision making (Drillings \& Serfaty, 1997).

Weick (1988) draws from Shrivastava's (1987) concept of triggering events in extreme contexts, which are discernable events that can be linked back to specific acts of human judgment and that can deteriorate under pressure (Staw, Sandelands, \& Dutton, 1981). We suggest that these are the critical intervention points for leadership where leader judgment and action (or inaction) can determine the potential influence of an extreme event on performance. We believe the identification and study of these trigger points is critical and that future research should determine how leaders identify and establish constraints, structures and opportunities that influence sense-making and performance at such critical points.

The transition from pre-extreme event to in situ may also have implications for the use of various forms of leader power. In both a laboratory study (Mulder \& Stemerding, 1963) and field study aboard an aircraft carrier (Mulder, Ritsema van Eck, \& de Jong, 1971), Mulder and colleagues showed that during extreme events leaders who exercise more power, are directive and decisive in their style, and are goal directed were more effective. These findings support the work cited above, and suggest that followers may have pre-established schemas whereby when an extreme event triggers those schemas their response is to accept more centralization of power and direction from their leaders (Bass, 2008; Downton, 1973). Yet, in the Mann Gulch disaster mentioned above, we see the potential for breakdown of command and control systems. Further, in analysis of the Mount Everest mountain climbing disaster, Kayes (2004) suggested authoritative leadership led to the team's inability to challenge assumptions, adapt and learn.

As we discuss later, we suspect that when extreme events are counter normative or fall within areas where well-practiced routines do not apply, the style of leadership that will be more successful will likely be more complicated than simply being autocratic or directive. Additionally, we have relatively little evidence on how the leadership dynamics present prior to entry into 
extreme contexts influences leadership dynamics during extreme events (i.e., are entrained), or afterwards for that matter. For example, based on the principles of idiosyncrasy credits (Hollander, 1964), leadership prior to an extreme event may build "credits," or as we suggested above, higher levels of trust, that can be "expended" during extreme events as formal and informal leaders exercise influence.

In line with the literature cited above, Dynes (1983) and Perrow (1984) reported that leadership during actual extreme events normally becomes more directive and transactional. While we noted conflicting findings of whether directive leadership is most effective in those contexts, we suggest the answer to that question may be more contingent. It is entirely plausible that the actions leaders take before an extreme event to build idiosyncrasy credits, allows them to be more directive during an extreme event based on the trust and confidence they have built prior. If insufficient, as the level of dependency followers have on their leaders for outcomes (e.g., death or injury) rises, they may challenge or discount those leaders (Hurst, 1995; Sweeney et al., 2009), such as occurred at Mann Gulch (Weick, 1993).

Finally, the Greek philosopher Heraclitus stated that "no man ever steps in the same river twice, for it's not the same river and he's not the same man." Similarly we propose that an important temporal phenomenon for future study is related to how people and organizations change or develop as they move into and out of extreme events. This can be either good (e.g., new knowledge and competencies, built confidence, or post-traumatic growth) or bad (e.g., post-traumatic stress) depending upon the nature of those experiences, sense-making processes used, and the leadership operating before, during, and after the event. Of particular interest is how experiencing extreme events impact future thoughts and behaviors at individual and collective levels differently than less extreme events, and how leadership may influence the ways these crucible experiences are interpreted effectively in order to accelerate development to address the next set of events.

\subsubsection{Post event}

Transitioning to the period after an extreme event, certain styles and orientations towards leadership may be required that helps the organization's social system to reconstitute (e.g., heal, learn, and bounce back) as well as restore systems, procedures and resources (Porfiriev, 1996). Concerning social aspects, Seifert (2007) suggests that to promote trust and relieve anxiety after crises, leaders need to be open and transparent and publicize ongoing efforts taken to restore processes and systems, reconstitute personnel and other resources; as well as identify the various forms of support available to members. Without such transparency, maladaptive myths and rumors can easily spread in extreme contexts (Gephart, 1984). This is a critical time, as after crises there is a tendency for followers to feel more vulnerable and are more willing to scrutinize their leaders (Hurst, 1995); as well as the organizational processes, culture and assumptions that guided actions (Bartunek, 1988).

Pearson and Clair (1998) indicated that organizations require what they called "psychic reorganization" after extreme events to restore individuals' assumptions about themselves and their organization and the world. Trauma from extreme events, for example, will have threatened individuals' sense of safety (Taylor, 1983), and can leave them with maladies such as battle fatigue or shell-shock (Belenky, Noy, \& Solomon, 1985). Repeated exposure to extreme events that cannot be controlled may over time create learned helplessness, leading to withdrawal and atrophy (McKean, 1994; Seligman, 1975). To rebuild a sense of personal safety, Janoff-Bulman and Frieze (1983) and Foldy et al. (2008) suggest ways leaders use sense-giving to persuade followers that they are not powerless to address future extreme contexts and events.

Staw (1980) further argues that organization members tend to seek justification when experiencing trauma, hoping to rationalize and justify the event and their reactions to it. Thus groups that conduct collective meaning-making to reflect upon traumatic events help members to better deal with negative psychological effects (Tedeschi \& Calhoun, 2004). Moxley and Pulley (2004) suggest that people need the opportunity to reflect in a supportive environment if they are to learn from hardships, requiring leadership that is empathetic and individually considerate and that offers sufficient levels of psychological safety to process events. Without such leadership, it is likely that organizations will fail to capture lessons learned or regress to old ways.

\subsection{Magnitude and probability of consequences}

The next two dimensions of extreme contexts are the potential magnitude of consequences from the threat and the probability of the consequence occurring. Leonard and Howitt (2007) and Laporte (2007) note that crises, disasters and similar events can vary in their extremity. Extremity is often defined in the literature based on scope or scale of damage or effects. For example, the Mann Gulch fire (Weick, 1993) and the 1996 Mount Everest climbing incidents (Kayes, 2004)-both which affected isolated and relatively small groups-have been considered as more limited; while events such as the Indian Ocean Tsunami (Athukorala \& Resosudarmo, 2005) or hurricane Katrina (Comfort, 2007) have been considered as more extreme or broader in terms of impact and consequences. Instead, we suggest that levels of extremity are best specified on clearly identified levels of analysis, based on the particular theoretical model and specification of the levels of the IVs and DVs being tested. For example, extremity may be perceived as higher to an individual than a larger group, as when in groups members may have a greater sense of safety (Little, 1964).

At whatever level of analysis researchers specify, we believe the level of extremity is first a function of the potential magnitude of consequences from the threat. For example, the potential for death would be more intense than potential for minor injury; while at the collective level the potential loss of one soldier would be less intense than for a loss of ten. A high potential magnitude of consequences by itself, however, may be insufficient to create an extreme context. Those consequences must have a sufficient level of probability of occurring for individuals to perceive the context in which they are operating in as extreme (Pearson \& Clair, 1998).

As the magnitude and probability increase, we would expect organizations to overcome some of the inertia and resistance to prepare for extreme events noted earlier (Pauchant \& Mitroff, 1992; Pearson \& Mitroff, 1993) and expend resources and effort to 
initiate purposive preparatory actions and be less complacent. Therefore we would expect inherent motivation and a more intense stance with associated shifts in organizational priorities and formations of unique interdependencies even before extreme events occur-as well as increased vigilance.

As the components of levels of extremity rise, these contextual effects can bear on organization members affect and cognition in numerous ways. Foremost, extreme contexts can produce terror, stress, and other emotive responses to fear (Arndt et al., 1997; Foa \& Kozak, 1986; Lazarus \& Alfert, 1964; Lazarus, Speisman, Mordkoff, \& Davison, 1962). Fear and other forms of stress in turn can evoke deep self-reflection (Setterlund \& Niedenthal, 1993); which depending on factors such as levels of self-efficacy (Bandura, 1997) or resiliency (Masten \& Reed, 2002), can be either facilitative or debilitating, potentially creating rumination and inaction when action is needed. Such psychological breakdown or withdrawal can occur if organization members' understanding of the world are overturned, leading to withdrawal, paralysis or perhaps an active seeking for meaning (Bowlby, 1969; JanoffBulman \& Frieze, 1983; Parks, 1971).

Sensory inputs from more extreme contexts are also likely highly vivid and salient (Fiske, 1991; Nisbett \& Ross, 1980). This can influence at least two major processes. First, we know that ease of recall can influence estimations of the probability of a future event based on the ease with which it can be imagined (i.e., the availability heuristic, Tversky \& Kahneman, 1982), thus raising estimations of the probability an extreme event can occur. For leaders, this may motivate their use of controls and constraints as preparatory measures (Dynes, 1983; Perrow, 1984). Secondly, research on dual processing models shows that information of higher salience promotes more deliberate processing (Petty \& Cacioppo, 1986). This can be countered, however, by the finding that in general judgment deteriorates under stress (Staw et al., 1981).

As the outcomes of leadership in extreme contexts can impact adverse consequences (e.g., death or destruction) there are inherent moral implications. Jones' (1991) framework of moral intensity may thus be applicable. Jones describes how moral dilemmas that have a greater potential magnitude of consequences, and higher probability of occurring, amongst other factors, are considered more morally intense, subsequently influencing patterns of cognition and increasing attention toward moral issues; thereby influencing leadership processes in unique ways (Butterfield, Treviño, \& Weaver, 2000; Ferrell \& Gresham, 1985; Hunt \& Vitell, 1986).

As magnitude and probability increase there is a concomitant need for capable leaders. Thus we may also expect followers to reassess the adequacy of their leaders. For example, Sweeney (in press) found that soldiers cognitively reappraised their trust in their leaders prior to going into combat and tended to weight their appraisal on aspects of leaders' task competence more so than the character of the leader. This suggests that if we look at leadership as an influence process, the factors that followers' focus on in granting influence may change.

\subsection{Proximity}

We propose that proximity serves as the fourth component comprising levels of extremity. Proximity can be conceptualized in several ways including physical, psychological and/or social. There are three important aspects of proximity that need to be considered in terms of defining extreme contexts, 1) the physical proximity of the specific set of organizational members under investigation to an extreme event; as defined earlier in terms of the increased magnitude of undesirable effects and probability of those effects occurring to those individuals, 2) the psychological or social proximity of members to the extreme event in the sense that those members affiliated with leaders and followers are potentially in harm's way, and 3) the location of leaders and followers in relation to each other in an extreme context; in that they can be operating together, or at a distance to each other. We suggest that physical, social and psychological proximity can independently, or through some interaction, impact how leaders and followers prepare for and perform in extreme contexts.

\subsubsection{Physical distance}

We think that some of the base work that has examined leadership at a 'distance' is relevant to the study of extreme contexts. This work has suggested that the impact of leadership styles and behaviors on followers may vary to the degree that leaders and followers are physically separated from one another. Antonakis and Atwater (2002) suggested that physical distance will determine the dynamics of the influencing process such as how leaders' behaviors are perceived and interpreted by followers. For example, in combat, leaders who share risks and hardships with soldiers are seen as more effective, trustworthy, and "in touch" (Little, 1964).

Some authors argue that distance may diminish the level of quality associated with interactions that occur between leaders and followers (Bass, 1998; Howell \& Hall-Merenda, 1999; Yagil, 1998), and may actually result in neutralizing the leader's impact in terms of being able to attend to followers' needs, provide timely recognition, and give appropriate direction. It is possible, as noted above, that the mere appearance that the leader has less timely information and is less aware of followers' needs and fears could potentially negatively impact their credibility and interactions with followers. Indeed, Klauss and Bass (1982) concluded that physical distance in general increased the need for communication in order to maintain sufficiently high levels of coordination. However, due to the entrainment of leadership noted earlier, physical distance may not necessarily translate into less effective leadership processes. Specifically, the nature of relationships built prior to an extreme event, such as cohesion and trust, may be more important psychological and social factors than physical distance in promoting effective leadership.

Although research examining the moderating effects of physical distance is at this point very preliminary, we do suspect that as leaders and followers become more distributed from each other (e.g., special forces teams operating in dispersed and remote locations), physical proximity is likely an important factor in determining the nature of leadership relationships. For example, 
Shamir (1995) reported that physically closer leaders were seen as more considerate and open to feedback, than those who were distant from followers. Yagil (1998) noted that leaders who are physically closer to their followers may be better equipped to deliver individually tailored confidence-building communications to followers, as well as to function as role models as compared to more distant leaders. Howell, Neufeld, and Avolio (2005) reported that transformational leaders had a more positive impact on follower performance in physically close versus distant positions. Perhaps being physically close facilitates transformational leaders' ability to model their support for the mission and values of the units and organizations they lead.

Based on the discussion above, how leaders and followers will perform in extreme contexts may depend in part on how the physical proximity of leaders and followers interacts with the level of perceived stress in the context and the nature of the risk experienced. It will be important for future research to explore differences in effects based on conditions such as: 1) where the leader only is at risk (e.g., the leader is a bomb expert or hostage negotiator and moves his team to safety but goes in himself to diffuse a bomb/situation), 2) where followers only are at risk (e.g., the general in the command post directing attacking units), 3 ) where both leader and followers are at risk (e.g., a SWAT leader enters a house with his squad), and 4) where only civilians/clients/ patients are at risk (e.g., an emergency room doctor who is not personally at risk but the patient is; or a disaster relief worker that responds to a disaster after the major risk has subsided). These aspects of exposure to risk may contextualize leadership dynamics in unique ways, which in total have not yet been explored in the leadership literature.

\subsubsection{Psycho-social distance}

Proximity may also be an important factor in conditions where organization members are not personally at risk, but those psychologically or socially close are. For example, the U.S. Army's Warrior's Ethos states "I will never leave a fallen comrade" (Department of Army, 2006). History is replete with examples of soldiers voluntarily risking or sacrificing their lives to save relatively few other soldiers, such as the two heroic Delta Force operators awarded the Medal of Honor in 1993 in Mogadishu for volunteering to attempt to save a downed helicopter crew. Yet in the same battle, while Army Rangers and Delta Force operators were in peril, a UN relief force from Pakistan and Malaysia delayed response, and some suggest that the lack of impetus was due in part to a lack of psycho-social closeness to U.S. forces (Bowden, 1999). Psycho-social proximity may thus influence the types of actions taken by organizations as well as various psychological effects on organization members.

We also suggest that the social distance between leaders and followers is an important factor. Early leadership scholars suggested that leaders should maintain adequate social distance from their followers in order to be effective (Martin \& Sims, 1956). It was reasoned that by maintaining such social or psychological distance the leader could remain impartial and somewhat distant from emotional concerns of followers. Yet in combat, both Little (1964) and Stouffer et al. (1965) report that leaderfollower social distance reduces with relationships becoming increasingly more informal as contexts become more extreme. Along these lines, Mack and Konetzni (1982, p. 3) suggested that when operating in a military command context, "the successful commander officer ....must learn to become as one with his ward room and crew; yet at the same time, he must remain above and apart." This duality deserves much greater attention by researchers to determine how psychological or social proximity influences leadership relationships in extreme environments.

We do suspect that leader-follower social closeness will translate into higher levels of cohesion and trust which are critical in extreme contexts (e.g., Department of the Army, 1950, 2008; Sweeney et al, 2009). For example, we know that a strong sense of social identification with the leader and unit mission results in greater feelings of belonging to a unit, and that those feelings become important to the individual's self concept (Ashforth \& Mael, 1989). For example, in conditions where high social identification exists, members of units experience reduced stress and are more willing to sacrifice for the good of the leader, the unit, and the mission (Belenky et al., 1985; Department of the Army, 1950). This collective identity may set the conditions for highly coordinated action, but also reduce followers' willingness to question leaders' directions. The ultimate balancing act for leaders in these situations may be to foster a shared leadership system where the leader both maintains authority yet can be questioned.

We know that when followers have higher levels of personal identification with their leaders, generally noted in the literature as charismatic, they are more willing to engage to support the leader's mission and vision and tend to align their self concepts more closely to what the leader represents and how the leader signals them of his or her approval or disapproval (Shamir, House, \& Arthur, 1993); and are more likely to desire to please and follow the leader without question (Conger, 1989; House, 1977). Followers may become so identified with a charismatic leader that they 'idolize' versus 'idealize' and attribute extraordinary capabilities to the leader, resulting in unquestioned obedience (Bass, 2008; Howell \& Avolio, 1992).

These effects of charismatic leaders have been described as emerging more often in situations where there is a crisis or extreme event (Weber, 1947). In such situations, followers are more prone to want to follow a leader's directive to the extent the leader is perceived as competent, confident and focused (Yukl, 2006). Yet, unless the leader has ample competence, confidence and focus, follower obedience could result in a unit making the completely wrong choice of actions such as occurred in the 1996 Mount Everest tragedy (Kayes, 2004). The foundational work on charismatic leadership may thus be directly relevant to how we examine psychological and social distance in extreme contexts. Such settings may provide what Klein and House (1995) described as fuel that sparks the "fire" between charismatic leaders and followers.

\subsubsection{Psychological proximity and teams}

Discussion of psychological proximity in extreme contexts lends itself to further discussion of team structure and functioning. Organizations that potentially operate in extreme contexts tend toward specialization, with teams and individuals typically 
assigned specific yet coordinated tasks and responsibilities that they must deliver on when operating under high levels of stress (Yukl, 2006). A leadership challenge that requires research to unravel is how leaders balance the flexibility that self-managed teams or units require while ensuring controls necessary for successful coordinated action to address an extreme event. This adaptive tension, which we take up in our discussion of adaptive leadership below, may be one of the most important areas for future research on extreme events and contexts.

What we have learned in the limited research on self-managed teams is that the leadership of successful teams does not just come from formal leaders. For instance, Druskat and Wheeler (2003) observed that more effective self-managed teams had leaders who relied less on legitimate means of authority and more on their expert or referent power to direct teams. Yet, we noted the potential failures if followers subordinate themselves to such expert or referent power blindly. Again, one possible buffer for the negative effects that personal or social identification can have on teams operating in extreme contexts is for leaders to instill their expectation for the team to challenge the leader's direction when warranted (Hackman, 1986). An example is the "two challenge rule" implemented for piloting planes in the United States to guard against co-pilots becoming so psychologically close to a pilot that they are hesitant to challenge directives. This rule sanctions co-pilots to challenge a directive at least twice if they feel it is misguided, at which point they can take over command of the plane in an emergency situation.

In sum, the underlying paradox in the points raised above is that in extreme contexts people expect, if not desire, someone to be in charge, largely to establish some level of perceived control. This heightened sense of vulnerability may provide the spark for leaders to control followers in support of their visions, leading to a potentially dangerous situation if those leaders are inept, unethical or otherwise ineffective (Howell \& Avolio, 1992). As extreme contexts often drive leaders to be directive (Dynes, 1983; Perrow, 1984) research is needed to assess whether leadership should instead (or under what conditions) be organized as a shared process from the outset. This is particularly warranted since leadership itself cannot be distinguished from the unique social dynamics of the context (Heifetz, 1994; Gronn, 2002).

\subsection{Form of threat}

The fifth primary component of extreme contexts is the form of the threat itself. In defining extreme contexts at the outset of this article, we stated that potential consequences could be classified as physical (e.g., death, injury, exhaustion), psychological (e.g., post-traumatic stress, shell-shock), or material (e.g., hurricane or fire damage to a city). Differing psychological and social effects that influence leadership likely occur based on these differing forms of the risk itself. For example, forms of physical threats might activate mortality salience in unit members (Arndt et al., 1997), where that response would be unlikely when instead faced with the loss of material possessions, which may instead activate threat responses based on self-esteem. Each form of threat also likely requires a different leadership response. For example, when faced with threats to psychological well-being, effective leadership may be that which facilitates unit members' coping (Janoff-Bulman \& Frieze, 1983; Moxley \& Pulley, 2004) or sensemaking (Foldy et al., 2008). In the face of physical danger, effective leadership may be that which spurs aggressive and purposive action (Gray, 1959). Thus as forms of threat change, follower needs change, and thus demands on leadership. Yet, research has not investigated these contingencies.

Further, as we will discuss under attenuators, individual and group responses to threats are influenced by a broad range of individual and group differences. For instance, Bunker (1986) reported that those individuals who felt less stress under threatening conditions were generally more optimistic, thought they had more control over their own fate, and had a higher tolerance for ambiguity. Bartone (1999) reported that individual hardiness can mitigate war-related stress, as do factors such as unit cohesion at group levels (Belenky et al., 1985). Based on the nature of the attenuator, it may be relevant to countering some forms of threat, and not others.

Finally, it is important to note that the forms of threat can also come in combination. German soldiers fighting on their home soil in WWII, for example, likely faced immediate physical threat simultaneous with psychological trauma experienced from killing and/or seeing other unit members or enemy forces killed, while also fearful for destruction of their nation's economy and infrastructure which threatened their and their family's future.

In extreme contexts, therefore, leaders likely face multifaceted and dynamic human reactions to varying forms of threat, requiring a mix of what we will later define as adaptive and administrative leadership. In sum, the three forms of threat (i.e., physical, psychological and material) can impose a plethora of contingencies on leadership, either separately or combined, that are simply too numerous to amply cover here.

\subsubsection{Summary of the dimensions of extreme contexts}

What is clear from the discussion thus far is that leadership is contextualized differently based on the five dimensions covered in Fig. 1. As leader effectiveness is dependent upon the context (Osborn et al., 2002), this suggests that different models of leadership may be more or less effective within each set of the various permutations of these five factors. Obviously, future research should further delineate how these processes work and the contingencies and causation under which they operate. One very important question is whether followers and groups have different models or implicit theories of optimum leader prototypes (Lord, Foti \& DeVader, 1984) for differing dimensions of extreme contexts; and if so, to determine the implications for leader development, selection, and assignment. For example, we noted that different types of leadership may be called for before, during, and after an extreme event. Another important question is how these prototypes impact the way followers respond to leaders in extreme contexts, and in turn the impact their responses have on how leaders lead. An equally important question is whether the power of being identified with the leader and organization can operate as a double edged sword, where followers tend not to question the leader in critical moments where psychological stress is overwhelming perhaps due to physical threats to one's safety 
or life. Finally, how leaders create the conditions for shared or distributed leadership and the effects such leadership has on the unit's motivation and performance are largely unexplored areas in the literature.

\section{Attenuators and intensifiers}

In Fig. 1, we indicate that adaptive leadership in extreme contexts may also be subject to factors that may either intensify or attenuate the level of extremeness experienced by leaders and followers. This is because extreme contexts are multilayered and generative. The level of extremeness is therefore related to the nature of the organization, as noted earlier, and the capabilities it has to respond to extreme events. We address these issues by introducing a set of attenuators (e.g., psychological, social, and organizational resources) that we propose will reduce the probability or magnitude of extremeness of an event and/or an organization's ability to respond; as well as a set of intensifiers (e.g. aspects of time and complexity) that will raise the level of extremeness experienced and/or reduce an organization's ability to respond.

As an example, we have defined an extreme context as one that may exceed an organization's capacity to counter. If a helicopter crashed, leaving a special forces' unit in austere terrain, the high level of training and necessary equipment available for operating in such conditions these units possess would attenuate the extremeness of the context, as compared, for example, to a supply unit in a similar crash. The level of extremity would be intensified, however, if that Ranger unit lost tangible organizational resources (e.g., communications equipment) in the crash or had low psychological resources (e.g., lower efficacy due to never operating in similar terrain, or low social resources (e.g., a newly formed unit with little task or social cohesion).

We frame these attenuators and intensifiers as 'real' versus merely perceptual (e.g., the special forces' unit actually has more applicable training and equipment). We recognize that individuals and groups will also likely vary in their perceptions and attributions toward the same context, estimates of their level of capability, or other factors. Such variance, biases, and errors in perceptions and attributions are well established in the social cognition literature (e.g., Moskowitz, 2005; Fiske, 1991; Nisbett \& Ross, 1980; Tversky \& Kahneman, 1982) so for space limitations we will not treat the expansive literature here. Finally, while our scope does not seek to provide a theory of extreme leadership, we do suggest managing attenuators and intensifiers may be critical "levers" for leadership interventions in extreme contexts as denoted by the dashed line in Fig. 1.

\subsection{Psychological resources as attenuators}

Beck, Emery, and Greenberg (1985) suggest that fear is experienced when the evaluation of a threat exceeds the evaluation of one's personal resources to face that threat. This is consistent with research on the broaden and build theory (Fredrickson, Tugade, Waugh, \& Larkin, 2003), which demonstrated that left unchecked, negative emotions such as fear narrow the scope of cognition and attention, limiting potential thought-action repertoires (i.e., a fight or flight response); while positive emotions broaden such potential repertoires, facilitating greater adaptability under stress. Fredrickson and colleagues hold that psychological resources such as efficacy and resiliency have an undoing effect, and "loosen the hold that a negative emotion has gained on that person's mind and body by dismantling or undoing preparation for specific action" (Fredrickson, 2001, p. 222). Weick (1988, p. 311) makes similar propositions, noting that beliefs that "I have capacity" and "capacity makes a difference" will help expand sense-making in organizations during crisis situations. This is consistent with Jervis (1976, pp. 374-375) who states that the "predisposition to perceive a threat varies with the person's beliefs about his ability to take effective counteraction... whether they are vigilant or defensive depends in large part on whether they can act effectively on the undesired information." Thus, as sense of efficacy and control increases, stress decreases, broadening thought and action in the face of crisis (George, 1986; Shepela et al., 1999; Weick, 1988).

Importantly, these effects of psychological resources do not just change perceptions of an extreme event and one's capacity to counter it, but enhance actual performance which could serve to attenuate the threat itself. While the scope of this paper does not provide for a full coverage of the potential psychological resources that can attenuate extremity, we highlight efficacy and resiliency as exemplars. Constructs such as hope (Snyder, Rand, \& Sigmon, 2002), optimism (Seligman, 1975), courage (Goud, 2005; Hannah, Sweeney, \& Lester, 2009), hardiness (Bartone, 1999) and others are certainly also relevant for future research.

Resilience in the face of extreme events has been identified as a critical capacity at both individual (Reich, 2006) and collective (Manyena, 2006) levels. Masten and Reed (2002) describe resilience at the individual level as a class of phenomena characterized by patterns of positive adaptation in the context of significant adversity or risk. For example, Bonanno, Galea, Bucciarelli, and Vlahov (2006) showed the importance of resilience for New York residents to recover psychologically from the 9/11 terrorist attacks. Manyena (2006) defines collective resilience in the context of disasters as "the intrinsic capacity of a system, community or society predisposed to a shock or stress to adapt and survive by changing its non-essential attributes and rebuilding itself." Resiliency would be extremely important in prolonged extreme contexts such as when an organization cycles in and out of extreme events (e.g., an active SWAT team) requiring the ability to 'bounce back' and reset for the next extreme event.

Forms of efficacy are also critical factors in facing extreme events. First, self-efficacy is defined as "beliefs in one's abilities to mobilize the motivation, cognitive resources, and courses of action needed to meet situational demands" (Wood \& Bandura, 1989, p. 48) and is formed through training and other mastery experiences, vicarious learning, social persuasion and sources of arousal (Bandura, 1997). Goud (2005) states that "belief and trust in one's capabilities (i.e., confidence) is a primary force in countering fears, risks, and the safety impulse" (p. 110). It is important for building teams to operate in extreme contexts to note that individual level efficacy and collective efficacy are entrained such that confidence in one's group enhances individual efficacy to 
perform; and in turn, the interactions of efficacious individuals promote emergent collective efficacy that drives group performance (Hannah, Avolio, Luthans, \& Harms, 2008).

Rusbult and Van Lange (2003) note that it is not just the power of the situation or the individual/collective that is relevant to understanding human behavior, but also the combined interactions that will help explain the most variance. For example, if members have beliefs in their team's potency and efficacy, they tend to experience greater strength in numbers (Hinsz, 2008) and would be expected to respond more affirmatively in an extreme context. Indeed, higher levels of group identification can even mitigate fear of death, but as noted above, decrease the chances of the leader being challenged by followers (Strachan et al., 2007).

Finally, we note that psychological resources need to be grounded and 'calibrated' or otherwise can lead to unrealistic optimism (Weinstein, 1980) or overconfidence (Lindsley, Brass, \& Thomas, 1995), which can create hubris or myopia or excessive risktaking (Sultan, Bungener, \& Andronikof, 2002) that leads to failure. This highlights the importance of training and other preparations before extreme events, as well as introspection and learning post-event as outlined earlier; it is critical organizations develop accurate assessments of their capabilities.

\subsection{Social resources as attenuators}

Extreme events often require collective and even multi-agency action. Thus theories of social network leadership (e.g., Balkundi \& Harrison, 2006) may be important to advance in this particular context. Kapucu (2006) for example highlights the critical role of boundary spanners in extreme events that can link networks of external resources to counter threats. As information exchange and coordination is normally problematic during extreme events (Turner, 1976) it is also critical to establish (and test) leadership and communications systems across internal and external networks prior to extreme events. For example, an intelligence network may need to connect into law enforcement and disaster relief networks in a manner that allows them to then leverage the resources and information of those other networks.

Further, psychological resources as discussed earlier can operate at collective and even organizational levels creating social resources (Cameron, Dutton, \& Quinn, 2003) such as organizational efficacy (Lindsley et al., 1995) and collective leadership efficacy (Hannah, Avolio, et al., 2008). Social resources such as unit morale, cohesion, and effective leadership are associated with less psychiatric causalities in combat as well as greater unit effectiveness (Belenky et al., 1985; Little, 1964); and supportive social networks can help individuals make meaning of traumatic experiences (Belenky et al., 1985; Tedeschi \& Calhoun, 2004). In a study of American Soldiers in WWII, for example, the second most frequent reason they stated they fought was for each other and unit solidarity (the first reason was to end the War) (Stouffer et al., 1965).

\subsection{Organizational resources as attenuators}

Tangible organizational resources such as technical, financial, or human resources are of course central to facing and attenuating extreme contexts (Quarantelli, 1988; Turner, 1976). This can be as simple as the number of sand bags available to stop a flood, water to combat a fire, or much more complicated sets of resource packages. Tangible resources are also related to other attenuators. For example, well developed social networks can increase access to resources. Further, tangible resources influence the level of psychological resources available such as means-efficacy, which is based on an individuals' belief in the quality and utility of the tools available for task performance (Eden, 2001). "Tools" can include resources such as implements (e.g., equipment and computers), other persons (e.g., coworkers, followers, and supervisors), or administrative systems (e.g., procedures and processes). Importantly, means-efficacy combines with self-efficacy to enhance performance (Eden, 2001; Walumbwa, Avolio, \& Zhu, in press).

Finally, organizational adaptability can be an important attenuator in extreme contexts. Adaptability involves the ability to change during periods of contextual shifts and uncertainty (Lengnick-Hall \& Beck, 2005). Adaptability is made more difficult in rapidly evolving situations with imperfect information. In such contexts, an organization's level of adaptability is tied directly to its ability to collect and make sense of complex information in its environment and adjust accordingly (Chakravarthy, 1982). As noted by Dutton and Duncan (1987, p. 291), threats to adaptability can occur when an organization becomes "locked into current patterns of responses not because they have become routine and habitual, but because the issues are perceived as non-resolvable due to a resource shortage." Therefore, organizational adaptability in extreme and novel contexts requires adequate resources and effective organizational communications systems that give organizational members the ability to share information and coordinate (Dunn, Lewandowsky, \& Kirshner, 2002; Marks et al., 2000).

Seifert (2007) notes that during extreme events flatter, more adaptive organizational structures will be more effective, and reduce rigidity, centralization, and formalization. According to Pulakos, Arad, Donovan, and Plamondon (2000), adaptive performance occurs when organizations are designed in ways that their members are allowed to solve problems creatively (e.g., Hatano \& Inagaki, 1986; Holyoak, 1991), and enable coping with uncertain and unpredictable work situations (e.g., Ashford, 1986; Edwards \& Morrison, 1994; Goodman, 1994; Hall \& Mirvis, 1995; Mumford et al., 2007; Weiss, 1984).

We believe this discussion suggests that these attenuators individually or in concert can lessen levels of extremity and increase an organizations' ability for adaptive leadership response. Further these attenuators are malleable or can otherwise be influenced by organizational leadership. Yet other factors may come to bear that can intensify an extreme context. We cover two here as examples of potential intensifiers: time and levels of complexity. Like the attenuators, aspects of time and complexity are not inherent in the definition of an extreme context, but can serve to intensify levels of extremity. 


\subsection{Time as intensifier}

Time may be an important intensifier in the form of time compression, duration, and frequency. Time compression means that an impending extreme event may shortly occur where a rapid reaction is required, limiting potential responses and decision windows. Note our earlier distinction between extreme events and extreme contexts. Extreme events will inherently have some level of time compression, such as a pilot flying a plane hit by birds who has to choose whether to return to the home airport, or to land on any available space large enough to accommodate the plane. An extreme context, however (e.g., manning a nuclear reactor) may not have immediate threat. When present, time compression reduces planning, coordination and decision cycles as well as the ability to employ resources (e.g., Shrivastava, 1987; Weick, 1993).

The duration of an extreme event may influence the ability of an individual, team, or an organization to respond to, learn from, and adapt to the event. In longer duration extreme contexts, organizations have the benefit of learning from experiences and cycling that knowledge back into ongoing operations. Prolonged extreme events, however, can add increased load to a team or organization and result in degenerating an organization's psychological, social and material resources. For example, in summarizing numerous combat studies, Kollett (1982) evidences that after an initial spike in psychological casualties at the beginning of combat, followed by a sharp reduction; such causalities then begin to increase over time from accumulated trauma. One study in WWII showed that at 200-240 days in combat, infantrymen generally tended to become neurotic or otherwise psychologically incapacitated, suggesting individuals do not get "used to" or desensitized to such extreme contexts.

Finally, the frequency with which extreme events occur has numerous potential impacts. Frequency will reduce novelty and thus increase the amount of foresight and expectation leaders and followers may have with potential threats and responses, impacting the amount of physical and psychological preparation as noted earlier. Therefore, less frequent events may be considered more extreme relative to organizational readiness. Indeed, through frequent repetition expertise can be formed that then enhance naturalistic decision making in future extreme events under conditions of time compression where those knowledge structures can be called upon (Drillings \& Serfaty, 1997). Conversely, as noted earlier, with high frequency there may be a certain level of desensitization to cues and indicators as extremeness becomes perceived as the norm.

Greater frequency of extreme events increases the load on an organization and also limits the time organizations can "reset" and reconstitute. If that time is not ample, the next event may be more extreme relative to the depleted level of organizational readiness. As noted earlier in discussion of preparation phases, this reset time is critical to prepare the unit psychologically, physically, and with material. Related to psychological aspects; while American infantrymen experienced some form of breakdown at 200 days in WWII, British soldiers lasted near 400 days; which has been attributed to Britain pulling soldiers off the front line for respite at much greater frequency (Kollett, 1982).

\subsection{Level of complexity as intensifier}

Complexity is also an important intensifier in extreme contexts. Complexity refers to environments that are highly dynamic due to interconnected and interdependent variables collapsing together in unexpected ways (Marion, 1999; Stacey, 1995). When complexity occurs, seemingly small events can interact to generate unpredictable outcomes (Cilliers, 1998; Marion \& Uhl-Bien, 2001; Snowden \& Boone, 2007; Uhl-Bien \& Marion, 2009). Moreover, complexity can be generated when many factors interact together (e.g., a war situation) or only a few (e.g., a burning house).

Complexity is inherent in Weick's (1988, p. 309) description of crises, where he states through social enactment, "Crises can have small, volitional beginnings in human action. Small events are carried forward, cumulate with other events, and over time systematically construct an environment that is a rare combination of unexpected simultaneous failures." Similarly, Pearson and Clair (1988, p. 62) state "the first assumption is that crises present 'wicked problems': They are highly uncertain, complex, and emotional events that can play multiple parties' interests against one another." Because extreme events often involve complexity dynamics, the study of how leaders and followers process and make sense of complexity in extreme and ill-defined contexts will be a useful area of future research (Mumford, Zaccaro, Harding, Jacobs, \& Fleishman, 2000; Mumford et al. 2007).

In extreme contexts complexity can come from many sources. One source is the multi-agency nature of many extreme events (Gharajedaghi, 1999; Quarantelli, 1988). In his review of crisis management, Quarantelli (1988) found that communications flow is often required both intra- and inter-organizational, from organizations to the public and from the public back to the organization, and within the various systems of the organization-creating complex information webs where both information or misinformation flows. The difficulties of information flow are compounded when greater numbers and varieties of agencies are involved. Further, social aspects such as a lack of inter-organizational trust can confound communications and information sharing in such contexts (Kapucu, 2006; Kapucu \& Van Wart, 2006).

Other sources of complexity can come from the interaction of people with technology, the level of uncertainty associated with rapidly changing, unpredictable conditions, and the number of critical events that are occurring simultaneously. As described by Quarantelli (1988), additional factors that intensify decision making in extreme contexts may come from competing priorities of responding agents due to things such as: 1 ) loss of higher echelon personnel due to overwork; 2) conflict over who has authority; 3) clashes over organizational domains between established and emergent groups; and, 4) surfacing of organizational jurisdictional differences. Finally, CAOs and some HROs are pitted up against enemy, criminals, or others purposively attempting to confound the extreme context and create complexity to thwart effective response. 
In sum, we have examined two intensifiers that can impact the level of extremity perceived by leaders, followers, organizations and teams. Certainly, there are other intensifiers yet to be explored that may also impact the level of extremity that require further research inquiry and discussion, that will serve to build out a model of leadership in extreme contexts.

\section{Adaptive leadership response}

We have proposed a taxonomy of five dimensions of extreme contexts, accompanied by attenuators and intensifiers that we hope helps to formulate a general understanding of the contextualization of leading and leadership in extreme contexts. As clarified up front, it is premature to develop a specific model of leadership for extreme contexts. The discussion thus far, however, has illuminated how the factors shown in Fig. 1 all ultimately influence the ability for adaptive leadership response as shown on the far right of the model. Thus we expect this model will provide some level of guidance for researchers to frame and test their theories with an appreciation of the multidimensional aspects of extreme contexts and extreme events.

Based on our literature review, here we make only general observations about the nature of leadership in extreme contexts and offer more questions than answers, with the intent to stimulate thoughts for future research. While much more specific differentiations are needed in the future, at this early point of theory-building we focus here on a general question, recurring throughout this paper, of the relative effectiveness of directive (or loosely related terms such transactional, administrative, or taskoriented) versus participative (or loosely related terms such as transformational, shared, or delegative) leadership. At the collective level, this general dichotomy can also be framed as adaptive versus administrative forms of organizing (Uhl-Bien, Marion, \& McKelvey, 2007; Uhl-Bien \& Marion, 2009). These categorizations find their roots in the early Ohio State and Michigan studies funded, aptly, largely to study military leadership.

\subsection{Leadership and adaptation to extreme contexts}

Research has noted that as forms of threat become overwhelming, individuals will look to leaders to centralize authority and take action (Gladstein \& Reilly, 1985; Isenberg, 1981). This effect may be particularly true when followers feel they lack adequate resources or structure to address the threat. Flanagan et al. (1952) observed that military leaders who took prompt and decisive action, providing initiating structure in threatening situations, were judged as being more effective than those military leaders who delayed action. Further, officers who used consultative power in non-crisis situations were seen as more effective by their followers, whereas in crisis situations the same style was not correlated with effectiveness (Mulder et al., 1986). This may be a reason underlying the findings of Sweeney and colleagues noted earlier (Sweeney, in press; Sweeney et al., 2009), as well as Kalay's (1983) study of Israeli soldiers operating in extended combat noting that perceptions of leader task competence is critical in extreme contexts. Yet research is needed to determine if this focus on leaders' task competence is an artifact of leaders not establishing norms for participative leadership in advance of extreme events as noted earlier. Returning to the entrainment of leadership, the expectation that followers have going in and that leaders reinforce may signal followers to look to the leader for control.

Similarly, strong informal structures and procedures coupled with the formation of similar values and identification in a unit may buffer or attenuate individuals against the negative effects of external threats (Gal \& Jones, 1985). Yet, in sustained exposure to threat it is possible that individuals or groups will become more rigid and less apt to challenge leaders' directions, reducing their ability to generate required responses over time (Staw et al., 1981). Under these types of extended threatening conditions, we see followers becoming more immobile and receptive to the type of personalized charismatic leaders described earlier (Downton, 1973).

Counter to the research above, Burgess, Riddle, Hall, \& Salas, (1992) concluded based on their review of the leadership and stress literature that effective leaders dealing with threats show greater receptivity of input from followers, integrate the efforts of their teams, and were more approachable and less intimidating. Such leaders were also more likely to explain their actions and decisions, and to communicate extensively. Research in combat, for example, has shown that leaders become closer to their soldiers and use less position power (e.g., reward or coercive powers) as situations get more extreme (Little, 1964). Many of the characteristics associated with such leadership can be characterized as being active transactional leadership, transformational leadership, and leaders who are seen by their followers as authentic (Avolio \& Luthans, 2006). In dealing with extended stress, leadership that provides competence, support, structure, priorities, role clarity, effective communication, coordination, maintains cohesion, focus, calm, a sense of humor and adequate preparation and response has typically been evaluated as more effective in very preliminary research on these topics (Weinberg, 1978; Ziegart, Klein, \& Xiao, 2002). These forms of leadership might maintain the high levels of identification required of units operating in extreme situations without necessarily compromising the authority of leadership systems.

This conflicting literature may be the result of studies being conducted under different conditions of extreme contexts, which reinforces why a typology is needed. If different dimensions of extreme contexts require different forms of leadership, leaders must be able adjust their leadership between more administrative and adaptive forms. Along these lines, Bass (2008) suggests that effective leaders dealing with stress and threats use transactional leadership to articulate goals and expectations and the pathways that need to be followed. He further states that transformational leadership can then augment performance by displaying care for follower welfare, inspiring through leading from the front, and by convincing followers they are part of a larger entity and mission, thus not isolated when confronted by threats.

In sum, we suggest research is needed to disentangle the relative effectiveness or proper mix of adaptive and administrative leadership in order to both provide sufficient structure as well as enable agentic behaviors that may be required to promote 
adaptability (Uhl-Bien \& Marion, 2009). Further, as we have noted that leadership is contextualized differently before, during, and after extreme events, differing mixes of such leadership may also be required across time.

Finding the right mix, however, may be problematic. In a complex extreme context, such as a large fire requiring the coordinated efforts of multiple fire companies, more administrative leadership may be required to prevent fratricide and the effective employment of resources which creates a tendency to consolidate administrative control (Hermann, 1963). Yet, we expect that hierarchical control systems may break down at certain levels of complexity in an extreme context, creating a threshold beyond which adaptive forms are needed. Indeed, in discussing organizational accidents, Perrow (1984) suggests excessive administrative control creates an overly tight "coupling," where once a problem in a system arises; it creates a chain reaction of events that can create or exasperate an accident as opposed to creating conditions for adaptation.

Effective organizations may thus have set the conditions for such adaptive forms to emerge through social interaction as needed. For example, in their case analysis of the Coast Guard during hurricane Katrina, Rego and Garau (2007) state that what made them successful was "improvisation." This is similar to what has in the learning literature been called an ambidextrous organization that can flex between exploitation and exploration (Hannah \& Lester, 2008; March, 1991). Such adaptability has been broadly defined as an effective organizational change in response to an altered situation (Pulakos et al., 2000). For example, in Vietnam the 450 man 1/7 Cavalry was isolated at a landing zone and facing an enemy regiment of 2000 men (as portrayed in the book and movie, We Were Soldiers Once and Young) (Moore \& Galloway, 1992). On day two of the battle the unit had 79 killed and 121 wounded and all administrative systems to resupply, reinforce, or evacuate the battalion became untenable. Facing another major enemy assault, the unit radioed 'broken arrow': a code for an American unit in imminent danger of destruction. At this threshold, administrative systems at higher headquarters for control were suspended-adaptive organizing kicked in-and all available combat aircraft in the entire combat zone were turned over to the unit to employ as needed.

The examples provided above highlight that different forms of leadership may be required at each of the direct, organizational, and strategic levels in extreme contexts (Yukl, 2006). Future research will be important to then investigate the inherent tensions between the adaptability required of organizations at the direct, tactical level, and the needs for administrative control at higher levels of the organization in which they are embedded.

From this discussion of adaptive and administrative organizing and our framing of extreme contexts, we can formulate a general definition of leadership for extreme contexts. We build from Yukl's (2006, p. 8) definition as a base and define leadership in extreme contexts as:

Adaptive and administrative processes of influencing others to understand and agree about what needs to be done and how to do it, and the process of facilitating individual and collective efforts to accomplish shared objectives and purpose under conditions where an extensive and intolerable magnitude of physical, psychological, or material consequences may exceed an organization's capacity to counter and occur to or in close physical, social, cultural, or psychological proximity to organization members.

\subsection{Methodological issues in examining leadership in extreme contexts}

Pursuing research on leadership in extreme contexts will require concomitant thinking about required methods for these contexts. This is because extreme contexts may have nonlinear effects and high levels of variance due to the volatility inherent in these contexts. Findings established in normal or routine contexts thus may not generalize well to extreme contexts and specific methodological approaches may be required regarding both the definition of constructs and assessing their relationships to various criteria.

A first area of attention will be the definition of constructs since those can be psychologically redefined when facing extreme contexts. For instance, does "trusting my peers" mean the same in a mundane office environment where the worst threat is office politics such as backstabbing, as compared to war or firefighting settings where the worst threat is the loss of one's and others' life? Does level of trust change as the context becomes more extreme?

Golembiewski, Billingsley, and Yeager (1976) propose a relevant distinction by considering changes in construct measurements of type alpha (meaning and measurement of construct is stable), beta (meaning is unchanged but measurement rule is recalibrated by respondent) and gamma (meaning is conceptually altered) (Golembiewski \& Billingsley, 1980; Thompson \& Hunt, 1996). Changes in dimensionality could also be important, distinguishing ipsative measures where a respondent has to rank different options, from normative measures, where respondents weight each option independently (Saville \& Willson, 1991). Indeed extreme contexts may present unique forced choices where one value (e.g., self-preservation) must be selected over another (e.g., desire not to kill). Finally, some constructs may be applicable only to-or most relevant to-extreme contexts. Constructs such as bravery (i.e., physical courage) or mortality salience, for example, operate only when exposed to physical risks.

A second area of attention will concern non-linearities in extreme contexts (Baum \& McKelvey, 2006; Daft \& Lewin, 1990; Starbuck, 1993). In the simplest case, linear relationships turn curvilinear when extending the range of context into the extreme. For example, typically, a leader creating higher levels of stress among followers in order to maintain vigilance may be beneficial to performance up to a certain level or point in time when stress may become very detrimental, exhibiting non-linear and detrimental effects beyond a certain level (e.g. Nelson \& Sutton, 1990).

Further, beyond the traditional approaches to theory development focused on expected outcomes (Mohr, 1982), we suggest studying extreme contexts requires that researchers consider modeling effects where there are high levels of variability in outcomes (e.g. Cabral, 2003; Denrell, 2003; Kalnins, 2007; March, 1991). Variability effects have already been theorized and demonstrated in various organizational studies (e.g., narcissism of leader in Chatterjee \& Hambrick, 2007; team demographic diversity in Fleming, 2004; culture in Sørensen, 2002, p. 70; team diversity in Taylor \& Greve, 2006). Methodologically, variability has been treated extensively in statistics 
literature (e.g. Tsetlin, Gaba, \& Winkler, 2004), including tools to deal with it such as quantile regressions (Greene, 2003, p. 448) or heteroskedasticity controls (Greene, 2003, chap. 11). Possible mechanisms to theorize effects on variability include amplifying mechanisms on spirals (George \& Jones, 2000; Hackman, 1990; Hambrick \& D'Aveni, 1988; Lindsley, Brass, \& Thomas, 1995; Weick \& Quinn, 1999). Beyond variability effects, various nonlinear phenomena can also be modeled in nonlinear ways (Meyer, Gaba, \& Colwell, 2005), such as discontinuities and jolts (Meyer, 1982), hyper turbulence (Meyer, Brooks, \& Goes, 1990) and oscillations (Gaba \& Meyer, 2008).

Finally, while complexity (Anderson, 1972) has been discussed in leadership literature (e.g., Uhl-Bien et al., 2007), empirical verifications of complex phenomena are challenging. A few examples, however, demonstrate how to detect for instance sensitivity to initial conditions and divergence (Gresov, Haveman, \& Oliva, 1993) or chaotic conditions (see Iran Hostage Crisis analysis in Thietart \& Forgues, 1997).

\section{Looking ahead and conclusions}

We have highlighted throughout this paper numerous areas that require research. Most of the literature on leadership in extreme contexts is based on rare cases (e.g., Chernobyl), thus this review is perhaps skewed by this limitation. To understand leadership in this context requires that a dedicated research program be initiated to study the various forms of contexts typified here, to include less rare cases such as the daily "routine" fire calls a fire department makes.

There are at least three important practical reasons for advancing this line of research. First, there is clear and direct application to the theory and practice of leadership in organizations with missions to respond to extreme events and their millions of members and clients they serve and protect around the globe. It is important that we examine the leadership dynamics that result in reliably successful performance in these contexts where 'failure is not an option'.

Second, this domain of research applies to an increasing number of naïve organizations that are unexpectedly engaged in extreme contexts. For example, just in the ten years after the 1999 Columbine High School massacre where 13 students and teachers were killed, there have been 26 more school attacks leaving 84 dead and scores more injured (School shootings, n.d.). Further, the FBI reports that since 9/11 seventeen terrorist attack plots have been thwarted in the U.S. alone, with additional averted plots not reported to the public for security reasons (CBS News, 2009). In response to heightened terrorist threat, organizations are implementing strict security procedures, practicing evacuation drills, and issuing emergency kits to employees. Every prominent hotel around the globe has to now consider events such as the November 2008 terrorist attack on two luxury hotels in Mumbai India that killed 160. Even grocery stores and water treatment facilities now have to consider the potential for mass poisonings. In sum, it appears that an increasing number of organizations may potentially operate in extreme contexts.

Third, a better understanding of leadership in extreme contexts will inform a deeper appreciation of the mechanisms and ontology of leadership processes and impact in general. By observing how definitions and applications of constructs, as well as the relationships between constructs, change across the span of conditions from low to high levels of extremity; we expect that we can gain a deeper understanding of how leadership operates. Highlighting these constraints and contingencies will perhaps challenge, provide additional evidence for, or further inform the validity of assumptions and boundaries of current models of leadership.

At this point of our thinking, we do not believe that studying leadership in extreme contexts will necessarily change our basic understandings of the essence of leadership. Nor do we think that the constructs currently in the literature will become inapplicable. We will likely continue to apply most extant theories to extreme contexts such as directive, transformational, or participative; or relational theories such as leader-member exchange, or information processing models such as implicit leadership theories to this context. We do believe, however, that the manner and effectiveness with which such models operate will be contextualized and that the unique qualities and characteristics of extreme contexts will create contingencies that alter the relationships between constructs in these theories; and will require advanced methodologies.

Finally, we approached this review with the assumption that there is little literature that has examined leadership in extreme contexts. While that assumption proved valid, we uncovered significantly more literature than expected that can be used to apply to and inform leading and leadership in extreme contexts. While largely not leadership research per se, the accumulated work cited informs aspects of individual, group, and organizational preparation for and responses to extreme contexts that can provide a base from which to launch this important new stream of leadership research.

\subsection{Conclusion}

We have entered into a dynamic and often unstable world where leadership matters in guiding select organizations through perilous conditions. Our principle goal in writing this review paper was to highlight as much about what we know as what we don't know in leadership theory and research about extreme contexts, while also linking relevant literatures to help launch new streams of theory and research in this dynamic area. We sought to explore the rich typology of extreme contexts and provide some level of explanation of how these factors influence leadership processes. Ultimately, we hope this discussion has provided additional building blocks to guide future theory-building and research to better understand the impact of leadership in extreme contexts. Indeed, many of the models of leadership already developed may well account for even higher levels of variance to the extent we apply them in the ways recommended to studying extreme contexts. We can also think of nothing more practical than learning about leadership that can facilitate individuals, teams, organizations; and for that matter, entire communities to anticipate and respond to those extreme events that characterize extreme contexts. 


\section{Acknowledgements}

The authors' foremost honor the untold millions of dedicated servants who have protected their nations' peoples and have sacrificed much in that calling; all too often paying the ultimate sacrifice. This work is drawn largely from their experiences, and hopes to serve them in return by promoting research that will ultimately inform the practice of leadership in extreme contexts. We would also like to thank the three anonymous reviewers who provided many substantive recommendations to improve this manuscript and the editorial team at The Leadership Quarterly.

\section{References}

Anderson, P. W. (1972). More is different. Nature, 177, 393-396.

Antonakis, J., \& Atwater, L. (2002). Leader distance: A review and proposed theory. The Leadership Quarterly, 13, 673-704.

Arndt, J., Greenberg, J., Pyszczynski, T., Solomon, S., \& Simon, L. (1997). Suppression, accessibility of death-related thoughts, and cultural defense: Exploring the psychodynamics of terror management. Journal of Personality E Social Psychology, 73, 5-18.

Ashford, S. J. (1986). Feedback-seeking in individual adaptation: A resource perspective. Academy of Management Journal, $29,465-487$.

Ashforth, B. E., \& Mael, F. (1989). Social identity theory and the organization. Academy of Management Review, 14, $20-39$.

Athukorala, P., \& Resosudarmo, B. P. (2005). The Indian Ocean tsunami: Economic impact, disaster management, and lessons. Asian Economic Papers, 4, 1-39.

Avolio, B. J. (2007). Promoting more integrative strategies for leadership theory building. American Psychologist, 62, $25-33$.

Avolio, B. J., \& Luthans, F. (2006). High impact leader: Moments matter in authentic leadership development. NY: McGraw-Hill.

Balkundi, P., \& Harrison, D. A. (2006). Ties, leaders, and time in teams: Strong inference about network structure's effects on team viability and performance. Academy of Management Journal, 49, 49-68.

Bandura, A. (1997). Self-efficacy: The exercise of control. New York: Freeman.

Bartone, P. T. (1999). Hardiness protects against war-related stress in Army reserve forces. Consulting Psychology Journal: Practice E Research, $51,72-82$.

Bartunek, J. (1988). The dynamics of personal and organizational reframing. In R. E. Quinn \& K. S. Cameron (Eds.), Paradox and transformation: Towards a theory of change in organization and management (pp. 137-162). Cambridge, MA: Ballinger.

Bass, B. M. (1985). Leadership and performance beyond expectations. NY: Free Press.

Bass, B. M. (1998). Transformational leadership: Industrial, military, and educational impact. Mahwah, NJ: Lawrence Erlbaum Associates.

Bass, B. M. (2008). Bass' handbook of leadership: Theory, research and managerial applications. NY: Free Press.

Baum, J. A. C., \& McKelvey, B. (2006). Analysis of extremes in management studies. In D. J. Ketchen \& D. D. Bergh (Eds.), Research methodology in strategy and management, Vol. 3. (pp. 125-199).

Beck, A. T., Emery, G., \& Greenberg, R. L. (1985). Anxiety disorders and phobias: A cognitive perspective. New York. Basic Books.

Belenky, G. L., Noy, S., \& Solomon, Z. (1985, July). Battle stress: The Israeli experience. Military Review, 11-20.

Benner, P. E. (1984). Stress and satisfaction on the job. NY. Praeger.

Boal, K. B., \& Hooijberg, R. (2000). Strategic leadership: Moving on. Leadership Quarterly, 11, 515-549.

Bonanno, G. A., Galea, S., Bucciarelli, A., \& Vlahov, D. (2006). Psychological resilience after disaster: New York City in the aftermath of the September 11th terrorist attack. Psychological Science, 17, 181-186.

Bowden, M. (1999). Black Hawk Down: A story of modern war. Berkeley, CA: Atlantic Monthly Press.

Bowlby, J. (1969). Attachment and loss. Volume 1: Attachment. London. Hogarth.

Bowman, E., \& Kunreuther, H. (1988). Post-Bhopal behaviour at a chemical company. Journal of Management Studies, 25, 387-402.

Bruning, J. L. (1964). Leadership in disaster. Psychology: A Journal of Human Behavior, 1, 19-23.

Bunker, B. B. (1986). Management training in Japan: Lessons for Americans. Proceedings, OD Network Conference, NY.

Burgess, K. A., Riddle, D. L., Hall, J. K., \& Salas, E. (1992, March). Principles of team leadership under stress. Paper presented at the 38th annual meeting of the Southeastern Psychological Association, Knoxville, TN.

Butterfield, K. D., Treviño, L. K., \& Weaver, G. R. (2000). Moral awareness in business organizations: Influences of issue-related and social context factors. Human Relations, 53, 981-1018.

Chakravarthy, B. S. (1982). Adaptation: A promising metaphor for strategic management. Academy of Management Review, 7, $35-44$.

Cabral, L. M. B. (2003). R\&D competition when firms choose variance. Journal of Economics E Management Strategy, 12, 139-150.

Cameron, K. S., Dutton, J. E. \& Quinn (Eds.). (2003). Positive organizational psychology: Foundations of a new discipline San Francisco, CA: Berrett-Koehlers Publishers.

CBS News. List of foiled terrorist plots since 9/11. Retrieved January 3, 2009, from: http://wcbstv.com/topstories/Terrorism.New.York.2.244858.html

Chatterjee, A., \& Hambrick, D. C. (2007). It's all about me: Narcissistic Chief Executive Officers and their effects on company strategy and performance. Administrative Science Quarterly, 52, 351-386.

Cilliers, P. (1998). Complexity and postmodernism: Understanding complex systems. London. Routledge.

Clarke, L. (2006). Worst cases: Terror and catastrophe in the popular imagination. Chicago: University of Chicago Press.

Comfort, L. K. (2007, Dec). Crisis management in hindsight: Cognition, communication, coordination, and control. Public Administration Review, 67(Supplement 1), 189-197.

Conger, J. A. (1989). The charismatic leader: Behind the mystique of exceptional leadership. San Francisco, CA: Jossey-Bass.

Cosby, N., Madden, J., Jacobs, R., Flynn, F., Sellars, J., Brown, G., et al. (2006). Generalized Non-Kinetic Operations (GNKO) Straw Man Task List. A report by Booz, Allen \& Hamilton for the Defense Advanced Research Projects Agency, Arlington Virginia.

Daft, R. L., \& Lewin, A. Y. (1990). Can organizational studies begin to break out of the normal science straitjacket? An editorial essay. Organization Science, 1 , 1.

D'Aveni, R. A., \& MacMillan, I. C. (1990). Crisis and the content of managerial communications: A study of the focus of attention of top managers in surviving and failing firms. Administrative Science Quarterly, 35, 634-657.

Denrell, J. (2003). Vicarious learning, undersampling of failure, and the myths of management. Organization Science, 14, $227-243$.

Department of the Army (1950). Pamphlet 600-2: The Armed Forces Officer. Washington DC: Defense Printing Service.

Department of the Army (2006). Army leadership: Competent, confident, and agile. Washington DC: Defense Printing Service.

Department of the Army (2008). TRADOC pamphlet 525-3-7-01: The human dimension in the future 2015-2024. Fort Monroe, VA.

Downton, J. V. (1973). Rebel leadership: Commitment and charisma in the revolutionary process. NY. Free Press.

Drillings, M., \& Serfaty, D. (1997). Naturalistic decision making in command and control. In C. E. Zsambok (Ed.), Naturalistic decision making (pp. 71-80).Mahwah, NJ, Erlbaum.

Druskat, V. U., \& Wheeler, J. V. (2003). Managing from the boundary: The effective leadership of self-managing work teams. Academy of Management Journal, 46, $435-457$.

Dunn, J. C., Lewandowsky, S., \& Kirsner, K. (2002). Dynamics of communication in emergency management. Applied Cognitive Psychology, $16,719-737$.

Dutton, J. E., \& Duncan, R. B. (1987). The creation of momentum for change through the process of strategic issue diagnosis. Strategic Management Journal, 8, 279-295.

Dynes, R. (1974). Organized behavior in disasters. Newark, Delaware: Disaster Research Center, University of Delaware.

Dynes, R. (1983). Problems in emergency planning. Energy, 8, 653-660.

Dynes, R., Quarantelli, E. L., \& Kreps, G. (1981). A perspective on disaster planning. Newark, Delaware: Disaster Research Center, University of Delaware. 
Eden, D. (2001). Means efficacy: External sources of general and specific subjective efficacy. In M. Erez, U. Kleinbeck, \& H. Thierry (Eds.), Work motivation in the context of a globalizing economy (pp. 65-77). Hillsdale, NJ: Lawrence Erlbaum.

Edwards, J. E., \& Morrison, R. F. (1994). Selecting and classifying future naval officers: The paradox of greater specialization in broader areas. In M. G. Rumsey, C. B. Walker \& J.H. Harris (Eds.), Personnel selection and classification (pp. 69-84). Hillsdale, NJ: Erlbaum.

Ember, C., \& Ember, M. (1992). Resource unpredictability, mistrust, and war. Journal of Conflict Resolution, 36, 242-262.

Ferrell, O. C., \& Gresham, L. G. (1985). A contingency framework for understanding ethical decision-making in marketing. Journal of Marketing, 49, 87-96.

Fiske, S. T. (1991). Social cognition, 2nd ed. New York. McGraw-ill.

Flanagan, J. C., Levy, S., et al. (1952). Development of an objective form of the leaders reaction test. Pittsburgh, PA. American Institute for Research.

Fleming, L. (2004). Perfecting cross-pollination. Harvard Business Review, 82, 22-24.

Foa, E. B., \& Kozak, M. (1986). Emotional processing of fear: Exposure to corrective information. Psychological Bulletin, 99, 20-35.

Fodor, E. M. (1978). Simulated work climate as an influence on choice of leadership style. Personality and Social Psychology Bulletin, 4, 111-114.

Foldy, E. G., Goldman, L., \& Ospina, S. (2008). Sensegiving and the role of cognitive shifts in the work of leadership. The Leadership Quarterly, 19, 514-529.

Fredrickson, B. L. (2001). The role of positive emotions in positive psychology: The broaden-and-build theory of positive emotions. American Psychologist, 56, $218-226$.

Fredrickson, B. L., Tugade, M. M., Waugh, C. E., \& Larkin, G. R. (2003). What good are positive emotions in crisis: A prospective study on resilience and emotions following the terrorist attacks on the United States on September 11th, 2001. Journal of Personality and Social Psychology, 84, 365-376.

Gaba, V., \& Meyer, A. D. (2008). Crossing the organizational species barrier: How venture capital practices infiltrated the information technology sector. Academy of Management Journal, 51, 976.

Gal, R., \& Jones, F.O. (1985). Psychological aspects of combat stress: A model derived from Israeli and other combat experiences. Unpublished manuscript.

Geller, W., \& Scott, M. S. (1992). Deadly force: What we know. Washington, DC: Police Executive Research Forum.

Gephart, R. P. (1984). Making sense of organizationally based environment disasters. Journal of Management, 10, 205-225.

George, A. L. (1986). The impact of crisis-induced stress on decision-making. In F. Solomon \& R. Q. Marston (Eds.), The medical implications of nuclear war Washington, DC: National Academy of Sciences Press.

George, J. M., \& Jones, G. R. (2000). The role of time in theory and theory building. Journal of Management, 26, 657-684.

Gharajedaghi, J. (1999). Systems thinking: managing chaos and complexity: A platform for designing business architecture, 2d ed. New York: Butterworth-Heinemann.

Gheytanchi, A., Joseph, L., Gierlach, E., Kimpara, S., Housley, J., Franco, Z. E., et al. (2007). The dirty dozen: Twelve failures of the Hurricane Katrina response and how psychology can help. American Psychologist, 62, 118-130.

Gladstein, D. L., \& Reilly, N. R. (1985). Group decision-making under threat: The tycoon game. Academy of Management Journal, $28,613-627$.

Glendon, A. I., Clarke, S. G., \& McKenna, E. (2006). Human safety and risk management, 2nd ed. Boca Raton, FL: CRC Press LLC.

Golembiewski, R. T., \& Billingsley, K. R. (1980). Measuring change in OD panel designs: A response to critics. Academy of Management Review, 5, 97.

Golembiewski, R. T., Billingsley, K., \& Yeager, S. (1976). The congruence of factor-analytic structures: Comparisons of four procedures and their solutions. Academy of Management Review, 1, 27.

Goodman, J. (1994). Career adaptability in adults: A construct whose time has come. Career Development Quarterly, 43, 74-84.

Goud, N. H. (2005). Courage: Its nature and development. Journal of Humanistic Counseling, Education, and Development, 44, $102-116$.

Grant, A. M., Campbell, E. M., Chen, G., Cottone, K., Lapedis, D., \& Lee, K. (2007). Impact and the art of motivation maintenance: The effects of contact with beneficiaries on persistence behavior. Organizational Behavior \& Human Decision Processes, 103, 53-67.

Gray, J. G. (1959). The warriors: Reflections on men in battle. New York: Harcourt Brace.

Greene, W. H. (2003). Econometric analysis, 5th ed. Upper Saddle River, N.J.: Prentice Hall.

Gresov, C., Haveman, H. A., \& Oliva, T. A. (1993). Organizational design, inertia and the dynamics of the competitive response. Organization Science, 4, 181.

Gronn, P. (2002). Distributed leadership as a unit of analysis. The Leadership Quarterly, 13, 423-451.

Hackman, J. R. (1986). The psychology of self-management in organizations. In M. S. Pollack \& R. O. Perloff (Eds.), Psychology and work: Productivity, change, and employment (pp. 89-136). Washington, DC: American Psychological Association.

Hackman, J. R. (1990). Groups that work (and those that don't): Creating conditions for effective teamwork, 1st ed. San Francisco: Jossey-Bass.

Hambrick, D. C., \& D'Aveni, R. A. (1988). Large corporate failures as downward spirals. Administrative Science Quarterly, $33,1$.

Hall, D. T., \& Mirvis, P. H. (1995). The new career contract: Developing the whole person at mid-life and beyond. Journal of Vocational Behavior, 47, $269-289$.

Hamby, J. E. (2002). The mutiny wagon wheel: A leadership model for mutiny in combat. Armed Forces \& Society, 28, 575-600.

Hannah, S. T., Avolio, B. J., Luthans, F., \& Harms, P. D. (2008). Leadership efficacy: Review and future directions. The Leadership Quarterly, 19, 669-692.

Hannah, S. T., Eggers, J. T., \& Jennings, P. L. (2008). Complex adaptive leadership: Defining what constitutes effective leadership for complex organizational contexts. In G. B. Graen \& J. A. Graen (Eds.), Knowledge-driven corporation: Complex creative destruction (pp. 79-124). New York: Information Age Publishing.

Hannah, S. T., \& Lester, P. B. (2008). A multilevel approach to building and leading learning organizations. The Leadership Quarterly, $20,34-48$.

Hannah, S. T., Sweeney, P. J., \& Lester, P. B. (2009). The courageous mindset: A dynamic personality system approach to courage. In C. Pury \& S. Lopez (Eds.), The psychology of courage: American Psychological Association.

Hannah, S. T., Woolfolk, L., \& Lord, R. G. (2009). Leader self-structure: A framework for positive leadership. Journal of Organizational Behavior, 30, $269-290$.

Hatano, G., \& Inagaki, K. (1986). Two courses of expertise. In H. Stevenson, H. Azuma, \& K. Hakuta (Eds.), Child development and education in Japan (pp. 262-272). New York: Freeman.

Heifetz, R. (1994). Leadership without easy answers. Cambridge, MA: Harvard University press.

Heimann, C. F. L. (1993). Understanding the Challenger disaster: Organizational structure and the design of reliable systems. The American Political Science Review, $87,421-435$.

Hermann, C. F. (1963). Some consequences of crisis which limit the viability of organizations. Administrative Science Quarterly, 8, 61-82.

Hermann, C. F. (1969). Crisis in foreign policy: A simulation analysis. Indianapolis: Bobbs-Merrill.

Hinsz, V. B. (2008). The social context of work motivation: A social-psychological perspective. In R. Kanfer, G. Chen, \& R. D. Pritchard (Eds.), Work motivation: Past, present, and future (pp. 553-568). New York: Routledge.

Hohenemser, C., Deicher, M., Ernst, A., Hofsäss, H., Lindner, G., \& Recknagel, E. (1986). Chernobyl: An early report. Environment, 28,6 -13.

Hollander, E. P. (1964). Leaders, groups, and influence. New York: Oxford University Press.

Holyoak, K. J. (1991). Symbolic connectionism: Toward third-generation theories of expertise. In K. A. Ericsson \& J. Smith (Eds.), Toward a general theory of expertise (pp. 301-335). Cambridge, England: Cambridge University Press.

Hopkins, A. (2001). Was Three Mile Island a 'normal accident'? Journal of Contingencies and Crisis Management, 9, 65-72.

House, R. J. (1977). A 1976 theory of charismatic leadership. In J. G. Hunt \& L. L. Larson (Eds.), Leadership: The cutting edge (pp. 189-207). Carbondale: Southern Illinois Press.

Howell, J. M., \& Avolio, B. J. (1992). The ethics of charismatic leadership: Submission or liberation? Academy of Management Executive, 6, $43-54$.

Howell, J. M., \& Hall-Merenda, K. E. (1999). The ties that bind: The impact of leader-member exchange, transformational and transactional leadership and distance on predicting follower performance. Journal of Applied Psychology, 84, 680-694.

Howell, J. M., Neufeld, D. J., \& Avolio, B. J. (2005). Leadership at a distance: The effects of physical distance, charismatic leadership, and communication style on predicting business unit performance. The Leadership Quarterly, 16, 273-286.

Hunt, S., \& Vitell, S. (1986). A general theory of marketing ethics. Journal of Macromarketing, 6, 5-16.

Hurst, D. K. (1995). Crisis and renewal. Boston: Harvard Business School Press.

Hynes, T., \& Prasad, P. (1997). Patterns of 'mock bureaucracy' in mining disasters: An analysis of the Westray coal mine explosion. Journal of Management Studies, $34,601-623$.

Isenberg, D. G. (1981). Some effects of time pressure on vertical structure and decision-making accuracy in small groups. Organizational Behavior and Human Performance, 27, 119-134. 
Janoff-Bulman, R., \& Frieze, I. H. (1983). A theoretical perspective for understanding reactions to victimization. Journal of Social Issues, 39,1 -17.

Jervis, R. (1976). Perception and misperception in international politics. Princeton, NJ: Princeton University Press.

Jick, T. D., \& Murray, V. V. (1982). The management of hard times: Budget cutbacks in public sector organizations. Organization Studies, 3, 141-169.

Jones, T. M. (1991). Ethical decision-making by individuals in organizations: An issue-contingent model. Academy of Management Review, 16,366 -395.

Kalay, E. (1983). The commander in stress situations in the IDF combat units during the Peace for Galilee campaign. Paper, Third International Congress of Psychological Stress and Adjustment in Time of War and Peace, Tel Aviv, Israel.

Kalnins, A. (2007). Sample selection and theory development: Implications of firms' varying abilities to appropriately select new ventures. Academy of Management Review, 32, 1246-1264.

Kapucu, N. (2006). Interagency communication networks during emergencies: Boundary spanners in multi-agency coordination. American Review of Public Administration, 35, 2-20.

Kapucu, N., \& Van Wart, M. (2006). The evolving role of the public sector in managing catastrophic disasters: Lessons learned. Administration E' Society, 38, 279-308.

Kayes, D. C. (2004). The 1996 Mount Everest climbing disaster: The breakdown of learning in teams. Human Relations, 57, $1263-1284$.

Kiesler, S., \& Sproull, L. (1982). Managerial response to changing environments: Perspectives on problem sensing from social cognition. Administrative Science Quarterly, 27, 548-570.

Klauss, R., \& Bass, B. M. (1982). Interpersonal communication in organizations. New York: Academic Press.

Klein, K. J., \& House, R. J. (1995). On fire: Charismatic leadership and levels of analysis. Leadership Quarterly, 6, $183-198$.

Kolditz, T. A. (2007). In extremis leadership: Leading as if your life depended upon it. Hoboken, NJ: John Wiley \& Sons.

Kollett, A. (1982). Combat motivation: The behavior of soldiers in battle. Boston: Kluwer-Nijhoff Publishing.

Kugihara, N., Misumi, J., Sato, S., \& Shigeoka, K. (1982). Experimental study of escape behavior in a simulated panic situation: Leadership in an emergency situation. Japanese Journal of Experimental Social Psychology, 21, 150-166.

LaPorte, T. R. (2007). Critical infrastructure in the face of a predatory future: Preparing for untoward surprise. Journal of Contingencies and Crisis Management, 15, $60-64$

Lazarus, R. S., \& Alfert, E. (1964). The short-circuiting of threat. Journal of Abnormal and Social Psychology, 69, $195-205$.

Lazarus, R. S., Speisman, J. C., Mordkoff, A. M., \& Davison, L. A. (1962). A laboratory study of psychological stress produced by a motion picture. Psychological Monographs, 76, 553

Lengnick-Hall, C. A., \& Beck, T. E. (2005). Adaptive fit versus robust transformation: How organizations respond to environmental change. Journal of Management, $31,738-757$

Leonard, H. A., Polich, J. M., Petterson, J. D., Sorter, R. E., \& Moore, S. C. (2006). Something old something new: Army leader development in a dynamic environment. Prepared for the United States Army by Rand Arroyo Center.

Leonard, H. B., \& Howitt, A. M. (2007). Against desperate peril: High performance in emergency preparation and response. In D. E. Gibbons (Ed.), Communicable crises: Prevention, response and recovery in the global arena (pp. 1-25). Charlotte, NC. Info Age.

Lindsley, D. H., Brass, D. J., \& Thomas, J. B. (1995). Efficacy-performing spirals: A multilevel perspective. Academy of Management Review, 20, 645-678.

Little, R. W. (1964). Buddy relations and combat performance. In M. Janowitz (Ed.), The new military: Changing patterns of organization NY: Sage.

Lord, R. G., Foti, R. J., \& DeVader, C. L. (1984). A test of leadership categorization theory: Internal structure, information processing, and leadership perceptions. Organizational Behavior and Human Performance, 34, 343-378.

Mack, W. P., \& Konetzni, A. H., Jr. (1982). Command at sea, 4th ed. Annapolis, MD: Naval Institute Press.

Manyena, S. B. (2006). The concept of resilience revisited. Disasters, 30, 434-450.

March, J. G. (1991). Exploration and exploitation in organizational learning. Organization Science, 2, 71.

Marion, R. (1999). The edge of organization: Chaos and complexity theories of formal social organizations. Newbury Park, CA: Sage.

Marion, R., \& Uhl-Bien, M. (2001). Leadership in complex organizations. The Leadership Quarterly, 12, 389-418.

Marks, M. A., Zaccaro, S. J., \& Mathieu, J. E. (2000). Performance implications of leader briefing and team-interaction training for team adaption to novel environments. Journal of Applied Psychology, 6, 971-986.

Martin, N. H., \& Sims, J. H. (1956). Thinking ahead: Power tactics. Harvard Business Review, 34, $25-36$.

Masten, A. S., \& Reed, M. J. (2002). Resilience in development. In C. R. Snyder \& S. Lopez (Eds.), Handbook of positive psychology (pp. 74-88). Oxford Uk. Oxford. Oxford University Press.

McConnell, A., \& Drennan, L. (2006). Mission impossible? Planning and preparing for crisis. Journal of Contingencies and Crisis Management, 14, 59-70.

McKean, K. J. (1994). Using multiple risk factors to assess the behavioral, cognitive, and affective effects of learned helplessness. Journal of Psychology, $128,177-183$.

Meyer, A. D. (1982). Adapting to environmental jolts. Administrative Science Quarterly, 27, 15.

Meyer, A. D., Brooks, G. R., \& Goes, J. B. (1990). Environmental jolts and industry revolutions: Organizational responses to discontinuous change. Strategic Management Journal, 11, 93.

Meyer, A. D., Gaba, V., \& Colwell, K. A. (2005). Organizing far from equilibrium: Nonlinear change in organizational fields. Organization Science, 16 , $456-473$.

Mintz, A. (1951). Non-adaptive behavior. Journal of Abnormal and Social Psychology, 46, 150-159.

Mohr, L. B. (1982). Explaining organizational behavior, 1st ed. San Francisco: Jossey-Bass.

Moore, H. G., \& Galloway, J. L. (1992). We were soldiers once... and young: Ia Drang-The battle that changed the war in Vietnam. New York: Random House.

Morath, R., Ccurnow, C., Cronin, C., Leonard, A, \& McGonigle, T. (2006). Identification of the competencies required of joint force leaders. Conducted by Caliber, ICF, for the Joint Staff.

Moskowitz, G. B. (2005). Social cognition: Understanding self and others. New York: The Guilford Press.

Moxley, R., \& Pulley, M. L. (2004). Hardships. In C. McCauley \& E. Van Velsor (Eds.), The Center for Creative Leadership handbook of leadership development, 2nd ed. San Francisco, CA: Jossey-Bass.

Mulder, M., de Jong, R. D., Koppeaar, L., \& Verhage, J. (1986). Power, situation and leaders' effectiveness: An organizational field study. Journal of Applied Psychology, $71,566-570$.

Mulder, M., Ritsema van Eck, J. R., \& de Jong, R. D. (1971). An organization in crisis and non-crisis situations. Human Relations, $24,19-41$.

Mulder, M., \& Stemerding, A. (1963). Threat, attraction to group, and need for strong leadership: A laboratory experiment in a natural setting. Human Relations, 16, 317-334.

Mumford, M. D., Friedrich, T. L., Caughron, J. J., \& Byrne, C. L. (2007). Leader cognition in real-world settings: How do leaders think about crises? The Leadership Quarterly, 18, 515-543.

Mumford, M. D., Zaccaro, S. J., Harding, F. D., Jacobs, O. T., \& Fleishman, E. A. (2000). Leadership skills for a changing world: Solving complex social problems. The Leadership Quarterly, 11, 11-35.

National Wildfire Coordinating Group. (2007). Leading in the wildland fire service. Boise, ID. National Interagency Fire Center.

Nelson, D. L., \& Sutton, C. (1990). Chronic work stress and coping: A longitudinal study and suggested new directions. Academy of Management Journal, 33, 859.

Nisbett, R. E., \& Ross, L. (1980). Human inference. Englewood Cliffs, NJ. Princeton-Hall.

Osborn, R. N., Hunt, J. G., \& Jauch, L. R. (2002). Toward a contextual theory of leadership. The Leadership Quarterly, 13, 797-837.

Parks, C. M. (1971). Psycho-social transitions: A field study. Social Science and Medicine, 5, 101-115.

Pauchant, T., \& Mitroff, I. (1992). Transforming the crisis-prone organization. Jossey-ass. San Francisco.

Pearson, C., \& Mitroff, I. (1993). From crisis-prone to crisis-prepared. Academy of Management Executive, 7, 48-59.

Pearson, C., \& Clair, J. A. (1998). Reframing crisis management. Academy of Management Review, 23, 59-76.

Perrow, C. (1984). Normal accidents. New York. Basic Books.

Perrow, C. (1997). Normal accidents: Living with high-risk technologies. Princeton, NJ: Princeton University Press.

Petty, R. E., \& Cacioppo, J. T. (1986). The elaboration likelihood model of persuasion. In L. Berkowitz (Ed.), Advances in experimental social psychology (pp. 123-205). New York. Academic Press. 
Porfiriev, B. (1996). Social aftermath and organizational response to a major disaster: The case of the 1995 Sakhalin Earthquake in Russia. Journal of Contingencies and Crisis Management, 4, 218-227.

Porter, L. W., \& McLaughlin, G. B. (2006). Leadership and the organizational context: Like the weather. The Leadership Quarterly, $17,559-576$.

Pulakos, E. D., Arad, S., Donovan, M. A., \& Plamondon, K. E. (2000). Adaptability in the workplace: Development of a taxonomy of adaptive performance. Journal of Applied Psychology, 85, 612-624.

Quarantelli, E. L. (1988). Disaster crisis management: A summary of research findings. Journal of Management Studies, 25, $373-385$.

Reich, J. W. (2006). Three psychological principles of resilience in natural disasters. Disaster Prevention Management, 15, $793-798$.

Rego, L., \& Garau, R. (2007). Stepping into the void. Greensboro, NC: Center for Creative Leadership.

Rodriquez, H., Wachtendorf, R., Kendra, J., \& Trainor, J. (2006). A snapshot of the 2004 Indian Ocean tsunami: Societal impacts and consequences. Disaster Prevention Management, 15, 163-177.

Rusbult, C. E., \& Van Lange, P. A. M. (2003). Interdependence, interaction, and relationships. Annual Review of Psychology, 54, 351 -375.

Saville, P., \& Willson, E. (1991). The reliability and validity of normative and ipsative approaches in the measurement of personality. Journal of Occupational Psychology, 64, 219.

Scales, R. H. (2006, January-February). The second learning revolution. Military Review, 37-44.

Schneider, B. (1987). The people make the place. Personnel Psychology, 40, 437-453.

Schneider, B., Goldstein, H. W., \& Smith, D. B. (1995). The ASA framework: An update. Personnel Psychology, 48, 747-779.

School shootings. (n.d.). Retrieved Jan 3, 2009: http://en.wikipedia.org/wiki/School_shooting

Schriesheim, C. A., \& Murphy, C. J. (1976). Relationship between leader behavior and subordinate satisfaction and performance: A test of some situational moderators. Journal of Applied Psychology, 61, 634-641.

Seifert, C. (2007). Improving disaster management through structured flexibility among frontline responders. In D. E. Gibbons (Ed.), Communicable crises (pp. 83-136). North Carolina. Information Age Publishing.

Seligman, M. E. P. (1975). Helplessness: On depression, development and death. San Francisco: Freeman.

Setterlund, M. B., \& Niedenthal, P. M. (1993). "Who am I? Why am I here?": Self-esteem, self-clarity, and prototype matching. Journal of Personality and Social Psychology, 65, 769-780.

Shamir, B. (1995). Social distance and charisma: Theoretical notes and an exploratory study. The Leadership Quarterly, 6, $19-47$.

Shamir, B., House, R. J., \& Arthur (1993). The motivational effects of charismatic leadership: A self-concept based theory. Organizational Science, 4, 1-17.

Shamir, B., \& Howell, J. M. (1999). Organizational and contextual influences on the emergence and effectiveness of charismatic leadership. The Leadership Quarterly, $10,257-283$.

Shepela, S. T., Cook, J., Horlitz, E., Leal, R., Luciano, S., \& Lutfy, E. (1999). Courageous resistance: A special case of altruism. Theory and Psychology, 9, 787-805.

Shrivastava, P. (1987). Bhopal: Anatomy of a crisis. Cambridge, MA. Ballinger.

Shrivastava, P., Mitroff, I., Miller, D., \& Miglani, A. (1988). Understanding industrial crisis. Journal of Management Studies, 25, $285-303$.

Smits, S. J., \& Ally, N. E. (2003). "Thinking the unthinkable"-Leadership's role in creating behavioral readiness for crisis management. Competitiveness Review, 13 , $1-23$.

Snook, S. A. (2000). Friendly fire: the accidental shootdown of U.S. Black Hawks over Northern Iraq. Princeton, N.J.: Princeton University Press.

Snowden, D. J., \& Boone, M. E. (2007, November). A leader's framework for decision-making. Harvard Business Review (pp. 68-76).

Snyder, C. R., Rand, K. L., \& Sigmon, D. R. (2002). Hope theory: A member of the positive psychology family. In C. R. Snyder \& S. J. Lopez (Eds.), Handbook of positive psychology. New York. Oxford Press.

Sørensen, J. B. (2002). The strength of corporate culture and the reliability of firm performance. Administrative Science Quarterly, $47,70$.

Sorokin, P. A. (1943). Man and society in calamity. NY. Dutton.

Stacey, R. D. (1995). The science of complexity: An alternative perspective for strategic change processes. Strategic Management Journal, 16 , $477-495$.

Starbuck, W. H. (1993). Keeping a Butterfly and an Elephant in a House of Cards: the Elements of Exceptional Success. Journal of Management Studies, $30,885-921$.

Starbuck, W. H., \& Miliken, F. J. (1988). Challenger: Fine-tuning the odds until something breaks. Journal of Management Studies, $25,319-340$.

Staw, B. (1980). Rationality and justification in organization life. Research in organizational behavior, Vol. 2. Greenwich, Connecticut. JAI Press.

Staw, B. M., Sandelands, L. E., \& Dutton, J. E. (1981). Threat-rigidity effects in organizational behavior: multi-level analysis. Administrative Science Quarterly, 26, $501-524$.

Stouffer, S. A., Lumsdaine, A. A., Lumsdaine, M. H., Williams, R. M., Smith, M. B., Janis, I. L., et al. (1965). The American soldier: Combat and its aftermath, Vol. 2. Princeton, NJ. Princeton University Press.

Strachan, E., Schimel, J., Arndt, J., Williams, T., Solomon, S., Pyszczynski, T., et al. (2007). Terror mismanagement evidence that mortality salience exacerbates phobic and compulsive behaviors. Personality and Social Psychology Bulletin, 33, 1137-1151.

Sultan, S., Bungener, C., \& Andronikof, A. (2002). Individual psychology of risk-taking behaviors in non-adherence. Journal of Risk Research, 5, $137-145$.

Sweeney, P. J. (in press). Do Soldiers re-evaluate trust in their leaders prior to combat operations? Military Psychology.

Sweeney, P. J., Thompson, V., \& Blanton, H. (2009). Trust and influence in combat: An interdependence model. Journal of Applied Social Psychology, 39, $235-264$.

Taylor, S. E. (1983). Adjustment to threatening life events: A theory of cognitive adaptation. American Psychologist, $1161-1173$.

Taylor, A., \& Greve, H. R. (2006). Superman or the fantastic four? Knowledge recombination and experience in innovative teams. Academy of Management Journal, $49,723-740$.

Tedeschi, R. G., \& Calhoun, L. G. (2004). Posttraumatic growth: Conceptual foundations and empirical evidence. Psychological Inquiry, $15,1-18$.

Tempest, S., Starkey, K., \& Ennew, C. (2007). In the death zone: A study of limits in the 1996 Mount Everest disaster. Human Relations, 60, 1039-1064.

Thietart, R. A., \& Forgues, B. (1997). Action, structure and chaos. Organization Studies, 18, 119.

Thompson, R. C., \& Hunt, J. G. (1996). Inside the black box of alpha, beta, and gamma change: Using a cognitive-processing model to assess attitude structure. Academy of Management Review, 21, 655-690.

Torrance, E. P. (1961). A theory of leadership and interpersonal behavior under stress. In L. Pertrullo \& B. M. Bass (Eds.), Leadership and interpersonal behavior NY: Holt, Rinehart \& Winston.

Tosi, H. L. (1991). The organization as a context for leadership theory: A multilevel approach. The Leadership Quarterly, 2, $205-228$.

Tsetlin, I., Gaba, A., \& Winkler, R. L. (2004). Strategic choice of variability in multiround contests and contests with handicaps. Journal of Risk and Uncertainty, 29, $143-158$.

Turner, B. A. (1976). The organizational and interorganizational development of disasters. Administrative Science Quarterly, 21 , $378-397$.

Tversky, A., \& Kahneman, D. (1982). Judgments of and by representativeness. In D. Kahneman, P. Slovic, \& A. Tversky (Eds.), Judgment under uncertainty: Heuristics and biases (pp. 84-98).Cambridge, UK. Cambridge University Press.

Uhl-Bien, M., \& Marion, R. (2009). Complexity leadership in bureaucratic forms of organizing: A meso model. The Leadership Quarterly, 20,631 -650.

Uhl-Bien, M., Marion, R., \& McKelvery, B. (2007). Complexity leadership theory: Shifting leadership from the industrial age to the knowledge era. The Leadership Quarterly, 18, 298-318.

Ulmer, W. F., Shaler, M. D., Bullis, R. C., DiClemente, D. F., \& Jacobs, T. O. (2004). Leadership lessons at division command level. Carlisle, PA. Army War College.

Union Carbide Corporation. (1985). Bhopal methyl isocyanate incident investigation team report. Danbury, CT: Union Carbide Corporation.

Useem, M., Cook, J. R., \& Sutton, L. (2005). Developing leaders for decision making under stress: Wildland firefighters in the South Canyon fire and its aftermath. Academy of Management Learning and Education, 4, 461-485.

VanVactor, J. D. (2007). Risk mitigation through a composite risk management process: The U.S. Army risk assessment. Organization Development Journal, 25, $133-138$.

Vaughan, D. (1996). The Challenger launch decision: Risky technology. Culture and deviance at NASA. Chicago, IL. The University of Chicago Press.

Walumbwa, F. O., Avolio, B. J., \& Zhu, W. (In Press). Transformational leadership, organizational commitment, and follower performance: The role of means efficacy and identification with the unit. Personnel Psychology. 
Weber, M. (1947). The theory of social and economic organizations. NY: Free Press.

Weick, K. E. (1988). Enacted sensemaking in crisis situations. Journal of Management Studies, 25, $305-317$.

Weick, K. E. (1990). The vulnerable system: An analysis of the Tenerife air disaster. Journal of Management, 16, $571-593$.

Weick, K. E. (1993). The collapse of sensemaking in organizations: The Mann Gulch disaster. Administrative Science Quarterly, $38,628-652$.

Weick, K. E. (1996). Drop your tools: An allegory for organizational studies. Administrative Science Quarterly, 41, $301-313$.

Weick, K. E., \& Bougon, M. G. (1986). Organizations as cause maps. In H. P. Sims Jr. \& D. A. Gioia (Eds.), Social cognition in organizations (pp. 102-135). San Francisco Jossey-ass.

Weick, K. E., \& Quinn, R. E. (1999). Organizational change and development. Annual Review of Psychology, 50, 361 -386.

Weick, K. E., \& Sutcliffe, K. M. (2001). Managing the unexpected: Assuring high performance in an age of complexity. San Francisco: Jossey-Bass.

Weick, K. E., Sutcliffe, K. M., \& Obstfeld, D. (1999). Organizing for high reliability: Processes of collective mindfulness. In R. I. Sutton \& B. M. Staw (Eds.), Research in organizational behavior, Vol. 21. (pp. 81-123). Elsevier Science/JAI Press.

Weinberg, S. B. (1978). A predictive model of group panic behavior. Journal of Applied Communication Research, 6, 1-9.

Weinstein, N. D. (1980). Unrealistic optimism about future life events. Journal of Personality and Social Psychology, 39, 806-820.

Weiss, S. J. (1984). The effects of transition modules on new graduate adaptation. Research in Nursing and Health, 7, 51-59.

Wong, L., Bliese, P., \& McGurk, D. (2003). Military leadership: A context specific review. The Leadership Quarterly, 14, 657-692.

Wood, R., \& Bandura, A. (1989). Impact of conceptions of ability on self-regulatory mechanisms and complex decision making. Journal of Personality and Social Psychology, 56, 407-415.

Wright, D. G. (1946). Anxiety in aerial combat. Research Publication of the Association of Nervous and Mental Disorders, 25, $116-124$.

Yagil, D. (1998). Charismatic leadership and organizational hierarchy: Attribution of charisma to close and distant leaders. The Leadership Quarterly, 9, $161-176$.

Yukl, G. (2006). Leadership in organizations, 2nd ed. Pearson. Upper Saddle River. NJ.

Zaccaro, S. J., Rittman, A. L., \& Marks, M. (2001). Team leadership. The Leadership Quarterly, 12, 451-483.

Ziegart, J., Klein, K., \& Xiao, Y. (2002). Team leadership: A review and extension of existing theory through a qualitative study of shock trauma teams. Denver. Academy of Management. 